\title{
OPEN Antisense oligonucleotide development for the selective modulation of CYP3A5 in renal disease
}

\author{
Kevin A. Lidberg ${ }^{1,7}$, Andrew J. Annalora ${ }^{2,7 凶}$, Marija Jozic ${ }^{2}$, Daniel J. Elson², Lu Wang ${ }^{3}$, \\ Theo K. Bammler ${ }^{3}$, Susanne Ramm ${ }^{4}$, Maria Beatriz Monteiro ${ }^{5}$, Jonathan Himmelfarb ${ }^{6}$, \\ Craig B. Marcus ${ }^{2}$, Patrick L. Iversen ${ }^{2} \&$ Edward J. Kelly ${ }^{1 \bowtie}$
}

CYP3A5 is the primary CYP3A subfamily enzyme expressed in the human kidney and its aberrant expression may contribute to a broad spectrum of renal disorders. Pharmacogenetic studies have reported inconsistent linkages between CYP3A5 expression and hypertension, however, most investigators have considered CYP $3 A 5 * 1$ as active and CYP $3 A 5 * 3$ as an inactive allele. Observations of gender specific differences in CYP $3 A 5 * 3 / * 3$ protein expression suggest additional complexity in gene regulation that may underpin an environmentally responsive role for CYP $3 A 5$ in renal function. Reconciliation of the molecular mechanism driving conditional restoration of functional CYP $3 A 5 * 3$ expression from alternatively spliced transcripts, and validation of a morpholino-based approach for selectively suppressing renal CYP3A5 expression, is the focus of this work. Morpholinos targeting a cryptic splice acceptor created by the $C Y P 3 A 5 * 3$ mutation in intron 3 rescued functional CYP $3 A 5$ expression in vitro, and salt-sensitive cellular mechanisms regulating splicing and conditional expression of CYP3A5*3 transcripts are reported. The potential for a G-quadruplex (G4) in intron 3 to mediate restored splicing to exon 4 in CYP3A $5 * 3$ transcripts was also investigated. Finally, a proximal tubule microphysiological system (PT-MPS) was used to evaluate the safety profile of morpholinos in proximal tubule epithelial cells, highlighting their potential as a therapeutic platform for the treatment of renal disease.

CYP3A5 (cytochrome P450, family 3, subfamily A, polypeptide 5) is a heme-thiolate monooxygenase that oxidizes a variety of xenobiotics and steroid hormones including cortisol and corticosterone ${ }^{1,2}$. CYP $3 A 5$ is the only CYP3A isoform expressed in the human kidney but genetic variants can affect expression level and activity ${ }^{2-4}$. Specifically, the $C Y P 3 A 5^{\star} 1$ allele encodes a full-length, functional enzyme while the $C Y P 3 A 5^{\star} 3$ allele contains a single nucleotide polymorphism $(6896 \mathrm{G}>\mathrm{A})$ in intron 3 generating a cryptic splice acceptor and nonsense mediated decay (NMD) of the aberrant $\mathrm{mRNA}^{5,6}$. CYP3A5 genotype contributes to interindividual differences in intrarenal disposition of drugs like cyclosporine and is postulated to modulate blood pressure, due to its ability to form and eliminate glucocorticoid receptor (GR) and mineralocorticoid receptor (MR) substrates influencing sodium retention ${ }^{7-10}$. CYP3A5 expression and activity is consistently correlated with blood pressure in animal models of hypertension ${ }^{8,11-13}$. However, attempts to establish a link between CYP3A5 genotype and hypertension in humans have yielded inconsistent outcomes ${ }^{14-19}$. The allele linkage may be complicated by the fact that $C Y P 3 A 5^{\star} 3{ }^{*} 3$ individuals can sometimes express functional CYP3A $5^{20}$. While the cellular mechanisms and environmental drivers regulating this conditional expression remain unclear, it is possible that hypertensive cohorts that include $C Y P 3 A 5^{*} 1 /{ }^{*} 3$ and $C Y P 3 A 5^{*} 3 /{ }^{*} 3$ individuals may not consistently predict outcomes associated with moderate or slow metabolizers ${ }^{20,21}$. The mechanism by which $C Y P 3 A 5^{\star} 3 /{ }^{*} 3$ individuals produce

\footnotetext{
${ }^{1}$ Department of Pharmaceutics, University of Washington, Seattle, WA, USA. ${ }^{2}$ Department of Environmental and Molecular Toxicology, Oregon State University, Corvallis, OR, USA. ${ }^{3}$ Department of Environmental and Occupational Health Sciences, University of Washington, Seattle, WA, USA. ${ }^{4}$ Victorian Centre for Functional Genomics, Peter MacCallum Cancer Centre, Melbourne, Australia. ${ }^{5}$ Depto Clinica Medica, Faculdade de Medicina FMUSP, Universidade de Sao Paulo, São Paulo, Brazil. ${ }^{6}$ Kidney Research Institute, University of Washington, Seattle, WA, USA. ${ }^{7}$ These authors contributed equally: Kevin A. Lidberg and Andrew J. Annalora. ${ }^{\square}$ email: Andrew.Annalora@oregonstate.edu; Edkelly@uw.edu
} 
functional CYP3A5 is unknown, but we hypothesized it may involve alternative splicing of precursor messenger RNA (pre-mRNA).

Alternative pre-mRNA splicing occurs in all human genes and provides functional expansion of the proteome $^{22,23}$. For the human cytochrome P-450 (CYP) family of 57 genes, alternative splicing increases the number of unique mRNA transcripts to nearly 1000, and may represent an adaptive mechanism to chemical exposure ${ }^{24}$. Recently it has been discovered that polyguanine sequences are overrepresented in RNA near splice sites where they can form G-quadruplex (G4)-RNA structures capable of altering pre-mRNA splicing patterns ${ }^{25}$. G4 structures observed in both intronic and exonic regions can act as either splice enhancers or splice silencers ${ }^{26-32}$. G4 RNA formation is strongly influenced by flanking nucleic acid sequence, and the local concentrations of RNA binding proteins and both monovalent and divalent cations ${ }^{33}$. Potassium $(\mathrm{K}+)$ is maintained at levels above $100 \mathrm{mM}$ in many cell types, and it is assumed to be the primary driver of G4 assembly in $v_{i v o^{34,35}}$. Alternative cations including sodium $(\mathrm{Na}+)$ are known to stabilize different $\mathrm{G} 4$ structures in vitro, while lithium $(\mathrm{Li}+)$ can be a G4 destabilizing agent ${ }^{33-36}$. Because G4 RNA structures respond to transient changes in intracellular cation levels they can conditionally-modulate gene expression and splicing events, as well as the function of non-coding $\mathrm{RNA}^{37}$. We hypothesize that the restoration of functional CYP3A5 expression observed for $C Y P 3 A 5^{\star} 3{ }^{*} 3$ polymorphs may be responsive to cellular stressors that influence renal cation storage and transport.

Here, we tested the hypothesis that a dynamic G4-motif located near the CYP3A5*3 SNP site regulates the cryptic, mutant splice acceptor in intron 3 , conditionally shifting spliceosome recognition back to the wild-type exon 4 splice acceptor. These studies were performed using a CYP3A5*3* 3 confirmed HEK293 cell line, and antisense oligonucleotides (ASOs) targeting the cryptic splice acceptor site $(6986 \mathrm{~A}>\mathrm{G}$; $r s 776746)$ or a putative G4 motif in intron 3. We previously showed the utility of using ASO interference to alter spliceosome function by targeting an exon splice-acceptor site in the $c$-myc transcript ${ }^{38}$. This strategy has now been used to restore the reading frame in mutant forms of dystrophin; create a ligand independent CTLA-4 splice variant; and modulate immune responses to Ebolavirus ${ }^{39-44}$. The current studies utilized synthetic oligomers to confirm the role of the ${ }^{*} 3 \mathrm{SNP}$ and a putative, intron $3 \mathrm{G}$-quadruplex in enhancing the exon 4 splice-acceptor in $C Y P 3 A 5^{\star} 3 /{ }^{*}$, which leads to restoration of functional enzyme expression under high salt conditions. Because some MR ligands generated by CYP3A5 promote sodium retention, renal CYP3A5 inhibition strategies may be appropriate for treating hypertension. However, most small molecule inhibitors of CYP3A5 also tend to inhibit CYP3A4, creating the potential for toxic, drug-drug interactions ${ }^{45,46}$. Recenlty, clobetasol propionate (clobetasol), a potent topical corticosteroid used to treat psoriasis, was identified as a potent and selective CYP3A5 inhibitor ${ }^{47,48}$. Here we demonstrate that CYP3A5 expression can alternatively be modulated using ASOs that interact with target RNA via Watson-Crick base pairing ${ }^{49,50}$.

The two chemistries usually employed for ASOs are phosphorodiamidate morpholino oligomers (PMOs) and phosphorothioate oligomers (PSOs). PSOs have phosphorothioate nucleic acid linkages with fully or partially (in the case of gapmers) substituted ribose rings at the $2^{\prime}$ position of various chemistry (e.g. O-methyl, OMe; $\mathrm{O}$-methoxyethyl, MOE), while PMOs have phosphorodiamidate linkages and morpholine rings. These chemical modifications affect several properties including protein binding, affinity for RNA, metabolic and renal clearance, and are required to achieve a pharmacologically relevant resident time in target tissue $\mathrm{e}^{51-53}$. PMOs and PSOs of various $2^{\prime}$-ribose chemistries are primarily eliminated by renal excretion, but they also accumulate in PTECs (proximal tubule epithelial cells), which can cause tubular degeneration and regeneration once the ASO surpasses a molecule-specific concentration threshold ${ }^{54,55}$. This is observed at lower doses for PSOs than PMOs and can be accompanied by increases in biomarkers of acute kidney injury (AKI) such as serum creatinine and urinary kidney injury molecule 1 (KIM-1). In addition, proteinuria is observed more often with PSOs than PMOs, though this may represent competitive inhibition of an uptake process ${ }^{56-61}$. Therefore, targeting CYP3A5 with ASOs is not without risk as nephrotoxicity is a safety liability for this class of molecules, although it may be chemistry-dependent and is usually mild and reversible ${ }^{62-64}$.

Screening strategies to select candidate ASOs with favorable safety profiles include in silico optimization of base sequence to maximize specificity and reduce off-target hybridization events as well as conventional toxicology studies in animals. However, ASO-induced toxicity can be sequence-dependent, making safety characterization of candidate molecules difficult ${ }^{65,66}$. Several candidate ASOs found to be well-tolerated in preclinical species caused AKI in first-in-human trials ${ }^{67-70}$. The mechanism by which ASOs cause renal injury remains largely unknown. Consequently, human-relevant in vitro cell culture models that can discriminate between safe and toxic ASOs as well as better describe and identify the molecular mechanisms of ASO-induced toxicity are needed.

We have developed a fluidic microphysiological system (MPS) populated with primary human PTECs that demonstrates many of the biochemical, synthetic, and transport activities of the proximal tubule ${ }^{71,72}$. PTECs within this system have promise in safety screening applications because they manifest physiological injury responses that discriminate between structurally similar compounds of differing toxicity ${ }^{73,74}$. Culture of PTECs in this MPS (proximal tubule-MPS, PT-MPS) enables biologically relevant cell-cell and cell-matrix interactions as well as application of shear stress, all of which are microenvironment factors that improve native cell phenotypes over conventional $2 \mathrm{D}$ cultures ${ }^{73,75-78}$. Here, we leverage this technology to compare the safety profile of a PMO to a 2'-OMe-PSO by quantifying cell associated and secreted biomarkers as well as performing global transcriptomic analyses with RNAseq.

\section{Results}

The CYP $3 A 5^{\star} 3$ variant ( $r$ s776746) is a common single nucleotide polymorphism (SNP) found within intron 3 of the human gene (Fig. 1a). The adenine nucleobase $(6986 \mathrm{~A} / \mathrm{G})$ altered by this mutation is highly conserved in non-human primates (Supplemental Fig. 1a), and the resulting polymorphism $\left({ }^{\star} 3-S N P\right)$ creates a pseudo-exon 


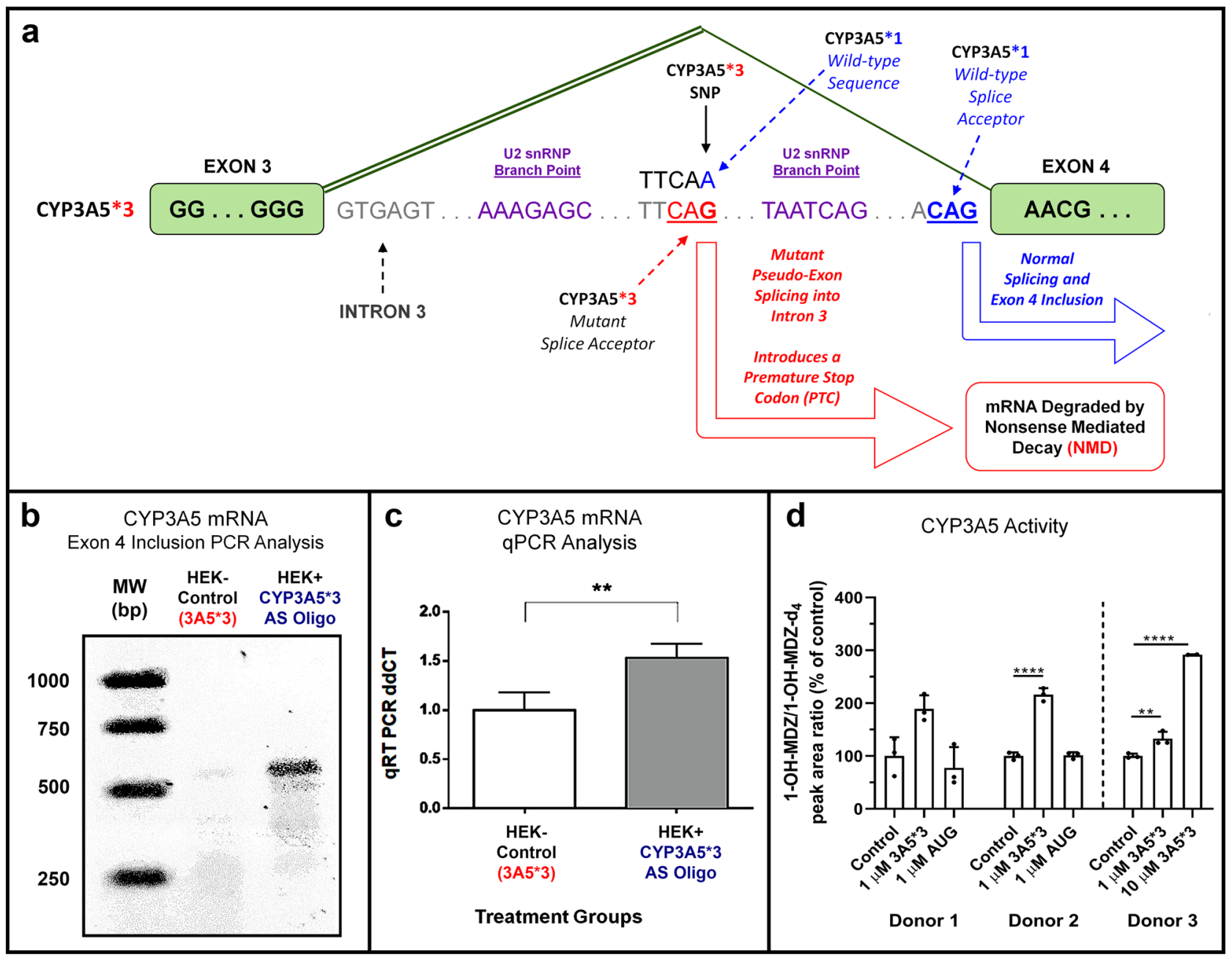

Figure 1. The $C Y P 3 A 5^{\star} 3$ SNP Regulates Gene Splicing via a Salt-sensitive Mechanism that can be Modulated with ASO in Renal Cell Culture Models. (a) Schematic for the CYP3A5^3/*3 polymorphism found in HEK293 cells. The CYP 3 A $5 * 3-S N P$ creates a cryptic splice acceptor within intron 3 that results in the aberrant splicing of a pseudo-exon containing a PTC that targets the mRNA transcript for degradation by NMD. Both the cryptic splice acceptor (CAG/TA) and the exon 4 splice acceptor (CAG/AA) are preceded by canonical U2 snRNP branch point cis-acting elements. (b) Endpoint PCR results monitoring exon 4 inclusion in mature CYP3A5 mRNA transcripts demonstrate the role of the ${ }^{\star} 3-S N P$ in altering splicing and transcript stability. Wild-type CYP3A5 mRNA transcripts encoding exon 4 are virtually undetectable (no band) in HEK293 cell lysates under normal conditions, however when the ${ }^{\star} 3$-SNP site is masked by interactions with an antisense oligomer (CYP3A5*3 PMO; $3 \mu \mathrm{M} ; 48 \mathrm{~h}$ ) transcript stability is restored, leading to enhanced detection of exon 4 inclusion via endpoint PCR. (c) Quantitative PCR (qRT-PCR; SYBR green) results demonstrating a 1.5-fold increase in total CYP3A5 mRNA when HEK293 cells were treated with the CYP3A5*3 PMO $(1 \mu \mathrm{M} ; 48 \mathrm{~h})$. (d) Quantification of the formation of 1-OH-midazolam from midazolam by LC/MS/MS after treatment with either $3 \mathrm{~A} 5 * 3 \mathrm{PMO}$ or AUG PMO for 6 days in primary human PTECs. CYP3A5 activity was increased in PTECs treated with $3 \mathrm{~A} 5 * 3 \mathrm{PMO}$ but not AUG PMO $\left({ }^{*} p<0.01\right.$; t-test). Efficiency of restoration of CYP3A5 activity by the $3 \mathrm{~A} 5^{\star} 3 \mathrm{PMO}$ was donor-dependent (Donor 3; See Supplemental Table 1), and was not related to cellular toxicity, as PMO treatments did not alter normal PTEC morphology (see Supplemental Fig. 9).

with a splice acceptor site in intron 3, with an intron/exon sequence (CAG/TA), that can compete with the reference sequence (CAG/AA) at the authentic exon 4 splice acceptor site (Fig. 1a). In addition, a U2 snRNP branch point sequence (AAAGAG) found upstream from the ${ }^{*} 3-S N P$, resembles the reference branch point (AATCAG ) near the exon 4 splice acceptor. Incorrect splicing of exon 4 at the ${ }^{\star} 3 S N P$ site creates a pseudo-exon with a termination codon, located upstream of the exon 4 splice acceptor site, capable of triggering NMD and loss of the CYP3A5 mRNA. To validate the role of the $6896 A / G$ polymorphism in creating the cryptic splice acceptor site in intron 3, an antisense oligonucleotide designed to bind to the SNP site was prepared, $3 A 5^{\star} 3 \mathrm{PMO}$ (Table 1). To clarify the role of the ${ }^{\star} 3-S N P$ in promoting NMD of mature transcripts, we explored the nature of CYP3A5 mRNA expression in a human embryonic kidney (HEK293) cell line, which was verified as homozygous ${ }^{*} 3 /{ }^{*} 3$ by DNA sequencing (Supplemental Fig. 1b). Incubation of HEK293 cells with the $3 A 5^{\star} 3$ PMO ( $\left.1 \mu \mathrm{M} ; 48 \mathrm{~h}\right)$, which masks the cryptic splice acceptor, led to increased levels of CYP3A5 mRNA as revealed by both endpoint PCR 


\begin{tabular}{|l|l|l|l|}
\hline Name & Sequence & Target & Purpose \\
\hline AUG & TTTCCCATGAGGTCCATCGCCAC & Translation start & Inhibit CYP3A5 synthesis \\
\hline 3 A5*3 & CAGGGAAGAGATATTGAAAGAC & 6986A/G SNP & Shift splicing to exon 3 \\
\hline G4 Disrupt & CCGATTCTGCAGCTGGAGCCACAC & G4 structure in intron 3 & Prevent G4 structure \\
\hline E4SA-3 & GAGTTGACCTTCATACGTTTCTG & Exon 4 splice acceptor & Skip exon 4; E4 EJC site \\
\hline E4SA-9 & TTGACCTTCATACGTTCTGTGTGGG & Exon 4 splice acceptor & Skip exon 4; E4 EJC site \\
\hline E4SA-17 & ACGTTCTGTGTGGGGACAACGG & Exon 4 splice acceptor & Skip exon 4; E4 EJC site \\
\hline E4SA + 94 & CAAAAAATGGATGCTTACCCTTCGA & Exon 4 splice acceptor & Skip exon 4 \\
\hline Scr & ACTCCATCGTTCAGCTCTGA & Scramble control & Negative control \\
\hline HPV PMO & CCTTTAGGGTAACAAGTCTTC & Human papillomavirus & Morpholino \\
\hline HPV PSO & CCTTTAGGGTAACAAGTCTTC & Human papillomavirus & 2'-OMe-PSO \\
\hline DSP PSO & UCAAGGAAGAUGGCAUUUCU & Dystrophin Exon 51 & 2'-OMe-PSO \\
\hline
\end{tabular}

Table 1. Antisense oligonucleotide sequences.

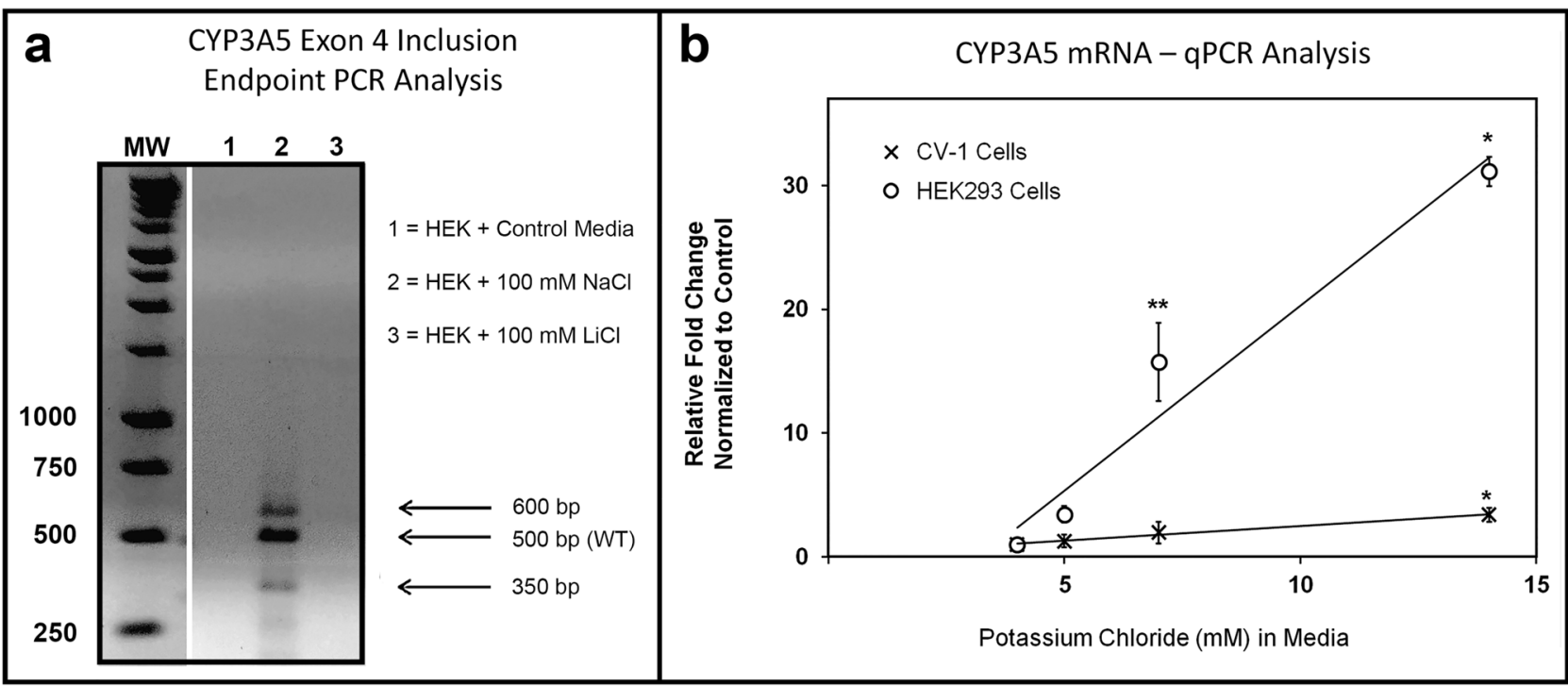

Figure 2. Cation-specific Restoration of $C Y P 3 A 5^{\star} 3 /{ }^{*} 3 \mathrm{mRNA}$ in HEK 293 cells, but not CYP $3 \mathrm{~A} 55^{\star} 1 /{ }^{\star} 1 \mathrm{CV}-1$ cells. (a) Endpoint PCR monitoring of CYP3A5 mRNA expression in HEK293 cells exposed to: 1 (control), 2 $(\mathrm{NaCl}$ enriched), and 3 ( $\mathrm{LiCl}$ enriched) media revealed cation-specific induction of alternative gene splicing. Several lanes were removed from this original gel image to aid in the molecular weight interpretation shown here, and this gap is denoted by the white dividing line. (b) SYBR Green qPCR Analysis of CYP3A5 mRNA from HEK293 $\left(C Y P 3 A 5^{\star} 3\right)$ and CV-1 $\left(C Y P 3 A 5^{\star} 1\right)$ cells incubated with media supplemented with increasing amounts of $(4,5,7$, and $14 \mathrm{mM})$ of $\mathrm{KCl}$. Normal DMEM media contains $4 \mathrm{mM} \mathrm{KCl}$.

(Fig. 1b) and quantitative (qRT) PCR (Fig. 1c). Functional restoration of CYP3A5 protein activity with the $3 \mathrm{~A} 5^{\star} 3$ PMO but not the (AUG) start site inhibitor, a PMO designed to block translation of all genotypes (Table 1), was confirmed in CYP3A $5 * 3 /{ }^{\star} 3$ primary human PTECs using a midazolam metabolism assay (Fig. 1d).

While the mechanism by which $C Y P 3 A 5^{*} 3{ }^{*} 3$ individuals produce functional CYP3A5 remains unknown, our results with the $3 A 5^{\star} 3 \mathrm{PMO}$ showed that blocking the ${ }^{\star} 3-S N P$ site can correct splicing and restore CYP3A5 activity in HEK293 cells. We hypothesized that a salt-sensitive, G4 structure located in proximity to the ${ }^{\star} 3$-SNP site might play a similar "trans-acting" role in driving alternative splicing of the pre-mRNA transcript. Computational analysis of the human CYP3A5 intron 3 gene structure identified multiple G4 targets in a repeating triplet $\mathrm{G}$ sequence spanning 151 bases located between the ${ }^{*}$-SNP and the exon 4 splice acceptor. A QGRS computational search of this region identified the signature of two conserved G4 structures at the $3^{\prime}$ end of intron 3 (see Supplemental Fig. 2) ${ }^{79}$. To validate the hypothesis that a G4 structure participates in CYP3A5 splicing and NMD suppression in CYP $3 A 5^{\star} 3$ genotypes, we tested the effect of G4-stabilizing, $\mathrm{Na}+$ cations on pre-mRNA splicing in cultured HEK293 cells. RNA extracted from HEK293 cells grown in standard media failed to produce a visible band indicative of normal exon 4 inclusion (Fig. 2a), while a visible band of expected size (500 bp) was present in RNA extracted from cells grown in hyperosmolar media (supplemented with $100 \mathrm{mM} \mathrm{NaCl}$ ). Two minor bands at 350 and 600 bp were also present in the PCR reaction but were not considered diagnostic for exon 4 inclusion. It is possible that these bands indicate additional complexity in exon 4 splicing under high salt 
conditions, but further analysis is required to rule out off-target PCR artifacts (Fig. 2a). A tonicity-responsive enhancer element located in intron 2 of the CYP3A7 gene, which regulates CYP3A family gene expression, has been previously described ${ }^{80}$. To discriminate the role of this cis acting element from the putative G4 element in intron 3 of CYP3A5, we supplemented HEK293 media with G4-destabilizing, $\mathrm{Li}+$ cations ( $\mathrm{LiCl} ; 100 \mathrm{mM})$ to raise osmolarity while destabilizing any G4 structures in the pre-mRNA transcript. Exon 4 inclusion bands were not observed in HEK293 cells treated with $\mathrm{LiCl}$, indicating that splice correction in ${ }^{*} 3{ }^{*} 3 \mathrm{mRNA}$ transcripts is cation-specific, and not simply a function of tonicity, further supporting a G4 element in proximity to ${ }^{*} 3$-SNP of CYP3A5 (Fig. 2a). To further establish the discrete role of the ${ }^{\star 3}$-SNP in mediating, cation-specific modulation of CYP3A5 expression in HEK293 cells, we utilized qPCR to compare the effects of hyperosmolarity on a related mammalian cell type (CV-1 cells; African Green Monkey Kidney Fibroblasts) expressing the CYP $3 \mathrm{~A} 5{ }^{\star} 1$ genotype (Fig. 2b); genomic sequencing has confirmed the green monkey does not express the human $(6986 \mathrm{~A} / G)$ SNP, similar to other non-human primates (Supplemental Fig. 1c). The relative fold change in wild-type CYP3A5 mRNA expression was monitored in both HEK293 and CV-1 cells using the $2^{-\Delta \Delta C T}$ method ${ }^{81}$. KCl supplementation (of 1,2 and $10 \mathrm{mM}$ to DMEM media containing $3 \mathrm{mM} \mathrm{KCl}$ ) had minimal influence on CYP3A5 expression in CV-1 cells, but significantly induced CYP3A5 mRNA transcript levels in HEK293 cells $\left({ }^{* *} p<0.01 ;{ }^{*} p<0.05\right.$; t-test), in a dose-dependent manner that supports the participation of a G4 structure (Fig. $2 \mathrm{~b}$ ).

A model depicting G4 structures in CYP3A5 intron 3 that modulate exon 4 splicing events is shown in Fig. $3 \mathrm{a}$. Cation-specific G4 stabilization of *3-SNP transcripts may shift the splice acceptor back to the reference exon 4 splice acceptor creating viable mRNA that bypasses pseudo-exon splicing and PTC incorporation that leads to altered translation of wild-type CYP3A5 or NMD of mRNA transcripts. We predicted ASOs targeting the G4 motif (called G4 Disrupt; Table 1) could prevent NMD escape and limit the cation-specific restoration of $* 3 / * 3$ transcripts in HEK293 cells. To test whether the proposed G-rich motifs in intron 3 could fold into G4-like structures in vitro, oligomeric DNA and RNA spanning the 151 base G-rich region of intron 3 was prepared (Table 2). Equal length oligomers containing the complementary C-rich sequences were used as controls. The DNA oligomers were incubated in the presence of $100 \mathrm{mM} \mathrm{KCl}$ and resolved on a native PAGE gel (Fig. 3b, Lanes $1-5)$. Multiple, differentially migrating bands were observed in lanes with the "G strand" DNA oligomer from intron 3 (Fig. 3b, Lanes 3-5); these bands were absent in matched "C-strand" experiments (Fig. 3b, Lanes 1-2). The G4 Disrupt PMO, with sequence complementary to the G-rich motifs identified by QGRS, had no effect on the C-strand mobility, but at high concentrations (fivefold molar excess) ablated the faster migrating bands in the G-strand (Fig. 3b, Lane 5). An RNA oligomer with sequence equivalent to the intronic DNA oligomer was used to establish G4 characteristics in the related RNA structure. Nearly all the intronic RNA formed faster migrating intra-strand G4 structures in the presence of $\mathrm{KCl}$ (Fig. 3c, Lane 1). Incubation with 1:1, 3:1, and 5:1 (G4 Disrupt) PMO to RNA ratios led to an increasing shift from fast migrating G4-like structures to the slower migrating linear form (Fig. 3c, Lanes 2-4).

Next, we tested the ability of the G4 Disrupt PMO to suppress cationic rescue of ${ }^{\star} 3 /{ }^{\star} 3$ transcripts in HEK293 cells incubated with $\mathrm{KCl}$ (Fig. 3d). Incubation with the G4 Disrupt PMO significantly blocked salt induction of viable CYP3A5 transcripts in HEK293 cells ( $48 \mathrm{~h} ., 1 \mu \mathrm{M}$; as compared to the scrambled (Scr) PMO control (Table 1); $p<0.01$ ) (Fig. 3d). Interestingly, CYP3A5 exon 4 skipping PMOs (Table 1) designed to target the CYP3A5 intron 3/exon 4 border may also alter the assembly of the exon junctional complex (EJC), as canonical eIF4AIII binding sites have been identified near their target site, 10-40 bp upstream of the splice junction, with a conserved EJC target site at 20-24 bp upstream ${ }^{82,83}$. Dex4 oligomers that bind downstream of the EJC, but not exclusively within exon 4 (Exon 4 Splice Acceptor PMOs (E4SA) -3 and -9, but not - 17 and + 94; see Table 1), were able to induce both wild-type and delta exon 4 (Dex4) CYP3A5 mRNA expression in HEK293 cells, without $\mathrm{NaCl}$ supplementation to the cell culture media (Fig. 3e). High salt levels appear to have altered the interaction of E4SA PMOs with target sequences near the EJC assembly zone, reducing the cationic-specific suppression of pseudo-exon inclusion and NMD, while enhancing the targeted skipping of exon 4 (Fig. 3e). These results highlight the dynamic splice sensitivity of CYP3A $5 * 3$ transcripts, that we attribute in part to a newly identified G4 element in intron 3. While more advanced biophysical methods (e.g., circular dichroism or NMR) are needed to fully characterize this theoretical secondary structural element, our data strongly support the existence of a conserved G4 element in intron 3 that alters the phenotypic presentation of $C Y P 3 A 5^{\star} 3$ genotypes via saltsensitive, alternative splicing and NMD suppression.

Western blot analysis was next used to confirm that in-frame $C Y P 3 A 5^{*} 3$ transcripts, rescued from NMD by $\mathrm{NaCl}$ or $\mathrm{KCl}$, can be translated into viable protein in HEK293 cells (Fig. 4a). We observed two CYP3A5 protein bands in our western blots, corresponding to the $\sim 56 \mathrm{KDa}$ reference protein, and a shortened, $\sim 30 \mathrm{KDa}$ splice variant. Total CYP3A5 protein expression increased when HEK293 cells were treated with increasing KCl (10-100 mM) or $100 \mathrm{mM} \mathrm{NaCl}$ (Fig. 4a,b, Lanes A-E), however the ratio of wild type to variant protein was reduced in all salt treatments compared to the HEK control (Fig. 4b, Lanes B-E). The salt-induced expression of both reference and variant CYP3A5 protein in HEK293 cells further supports the hypothesis that a G4 structure can masks the cryptic splice acceptor formed by the ${ }^{\star} 3$-SNP and alter the structure of the EJC at the CYP3A5 intron3/exon 4 border. Two models to explain this alternative splicing, where the G4 motif serves as either an internal ribosomal entry site (IRES) or an exonic splicing enhancer (ESE) element that can influence the availability of translational initiation start sites, are proposed in Supplemental Fig. 3.

The functional activity of salt-induced CYP3A5 expression was next confirmed by observing CYP3A-specific metabolic activity in HEK293 cells based on the conversion of 7-benzyloxy-4-[trifluoromethyl]-coumarin (BFC) to 7-hydroxy-4-[trifluoromethyl]-coumarin (HFC). As shown in Fig. 4c, HEK293 cells treated with KCl (12 mM; $48 \mathrm{~h}$.) showed a significant increase in CYP3A enzyme activity that was not suppressed when cells were co-treated with a scramble control (Scr) PMO ( $p<0.01$; t-test). In contrast, co-treatments with either the G4 Disrupt PMO or the start-site targeting (AUG) PMO (Table 1) significantly reduced CYP3A enzyme activity to levels observed for untreated HEK293 cells. CYP3A5 is also known to catalyze the endogenous conversion of glucocorticoids, 


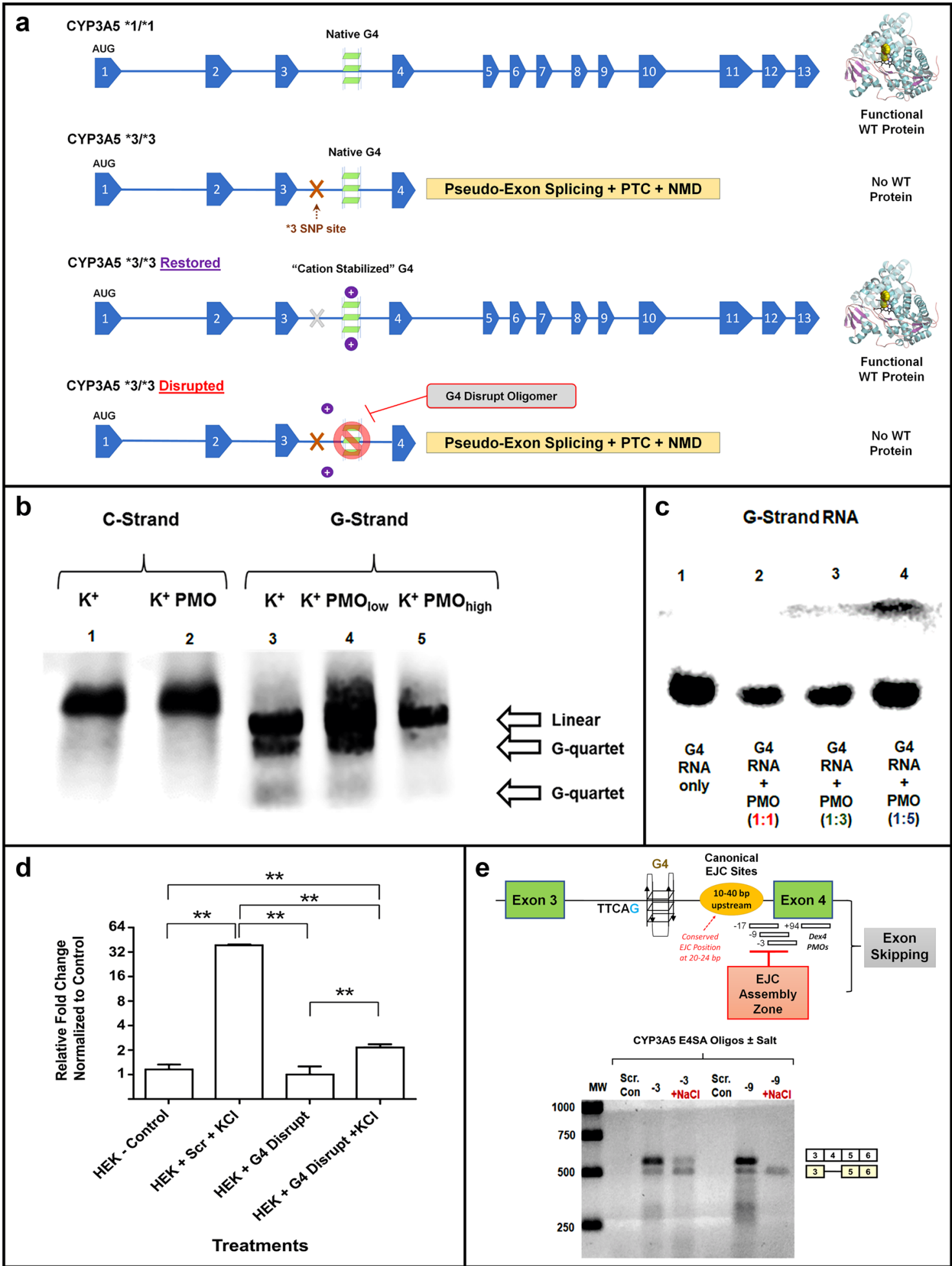


«Figure 3. G4 Structures Regulate CYP3A5 Expression and Represent Novel Targets for ASO Modulation. (a) Schematic diagram of the CYP3A5 gene showing the location of a putative G4 motif in Intron 3. Cation-specific stabilization of native G4 structure shifts the splice acceptor back to the reference exon 4 splice acceptor, creating an in frame $C Y P 3 A 5^{*} 3 /{ }^{*} 3$ transcript that bypasses pseudo-exon introduction and suppression of wild-type protein translation via PTC or NMD-related mechanisms. Salt-sensitive splice correction of $* 3$ transcripts (shown in Fig. 2a) can be abrogated using the G4 disrupting PMO (Table 1). (b) Computational analysis of the CYP3A5 gene (see Supplemental Fig. 2) and RNA/DNA gel shift assays (shown here), confirmed the existence of a G4-like structure in the CYP3A5 intron 3 region. Control lanes 1 and 2 depict the mobility of the 151 nucleobase, CYP3A5 intron 3 "C-strand" DNA, in $\mathrm{KCl}$-enriched running buffer [100 $\mathrm{mM} \mathrm{KCl}$ ]. The C-strand does not display faster migration typical of a G4 structure in the presence of KCL, and a G4 disrupting PMO does not alter C-strand mobility (lane 2). In contrast, the 151 nucleobase "G-strand" DNA demonstrated enhanced mobility bands reflecting both inter- and intra-strand G4 formation in KCl-enriched running buffer (lane 3). Addition of the G4 disrupting PMO diminishes the enhanced mobility bands at low concentration (1:1 molar ratio; lane 4) and ablates the enhanced mobility bands at high concentration (5:1 molar ratio; lane 5). (c) A 151 nucleobase RNA strand also forms a putative G4-structure in KCl-enriched running buffer (Lane 1). Addition of increasing amounts of G4 disrupting PMO to the G4 RNA (Lane 2 - 1:1 PMO:RNA ratio, Lane 3 - 3:1 PMO:RNA ratio, and Lane 4 - 5:1 PMO:RNA ratio) shifts the RNA structure to the slower mobility form. (d) qPCR analysis of CYP3A5 mRNA from HEK293 cells exposed to no PMO and normal media (HEK control), scramble PMO $(1 \mu \mathrm{M}, 48 \mathrm{~h}$.) and $\mathrm{KCl}(12 \mathrm{mM})(\mathrm{HEK}+\mathrm{Scr}+\mathrm{KCl})$, G4 disrupting PMO only $(1 \mu \mathrm{M}$, 48 h.) (HEK+ G4 Disrupt), and G4 disrupting PMO (1 $\mu \mathrm{M}, 48$ h.) and $\mathrm{KCl}(12 \mathrm{mM})(\mathrm{HEK}+\mathrm{G} 4 \mathrm{Disrupt}+\mathrm{KCl})$. Significant statistical differences were monitored by ANOVA; $p$ value $<0.01$. Post test $p<0.01={ }^{* *}$. (e) $($ Top $) \mathrm{A}$ schematic illustrating the location of the EJC in relation to the cryptic splice acceptor in intron 3 and the G4 structure. PMOs designed to skip exon 4 in CYP3A5 are also shown $(-17=\mathrm{E} 4 \mathrm{SA}-17,-9=\mathrm{E} 4 \mathrm{SA}-9,-3=\mathrm{E} 4 \mathrm{SA}-$ 3 , and $+94=$ E4SA +94). (Bottom) Endpoint PCR results for RNA expression in HEK293 cells treated with three PMOs (E4SA-3, E4SA-9, or a scramble control (Scr); $1 \mu \mathrm{M} ; 48$ h.) and $100 \mathrm{mM} \mathrm{NaCl}$ are shown. The Scr. oligomer did not induce stable transcripts, while exon 4 skipping PMOs (E4SA -3 and -9) induced transcripts that both include and exclude exon 4 . The addition of high salt media diminished the cell's ability to express transcripts including exon 4. Cationic-specific stabilization of the transcript may have improved the ability of exon skipping PMOs to properly bind the transcript near the EJC assembly zone and promote targeted exon 4 exclusion. Molecular drawings were generated using The PyMOL Molecular Graphics System, Version 1.3, Schrödinger, LLC.

including cortisol and corticosterone, to $6 \beta$-hydroxylated products that stimulate mineralocorticoid receptor (MR) activity. LC/MS/MS analysis was used to confirm the HEK293 cell-based conversion of parent cortisol to $6 \beta$-hydroxycortisol $(6 \beta \mathrm{OH})$ metabolites (see "Methods"). As shown in Fig. 4d, HEK293 cells incubated in normal media supplemented with cortisol $(1 \mathrm{nM} ; 24 \mathrm{~h})$ produced sixfold less $6 \beta$-hydroxycortisol metabolite (AU $\left.\mathrm{C}=1.93 \times 10^{-3} \pm 0.05 \times 10^{-3}\right)$ compared to HEK293 cells cultured in KCl-enriched media $(12 \mathrm{mM}$; AUC $=1.19 \times$ $10^{-2} \pm 0.48 \times 10^{-2} ;{ }^{*}<0.05 ; p=0.031 ;$ t-test). Enhanced $6 \beta$-hydroxycorticosteroid production was subsequently confirmed to significantly increase MR signaling activity (more than twofold) in a luciferase-based cell reporter system ( $p<0.01$; t-test; see "Methods") (Fig. 4e).

Given that CYP3A5 activity may exacerbate high blood pressure (HBP) in both fast metabolizing ${ }^{\star} 1 /{ }^{\star} 1$ and slow metabolizing (or conditional) ${ }^{\star} 1 /{ }^{\star} 3$ and ${ }^{\star} 3 /{ }^{*} 3$ genotypes, and this pathological activity can be modulated with ASO in vitro, developing CYP3A5-directed therapeutics targeting renal disorders is worth consideration. To advance in vivo development of a CYP3A5-specific antisense inhibitor, we next utilized our human kidney PT-MPS to evaluate whether ASO safety towards target PTECs would depend on the charge of the antisense backbone chemistry (e.g., neutral PMO or (-) charged PSO) (Fig. 5a). Hemeoxygenase-1 (HO-1) is strongly induced in PTECs after exposure to nephrotoxic compounds, including those that promote generation of reactive oxygen species, making it a good biomarker for this safety study ${ }^{74}$. KIM-1 is a widely-accepted urinary biomarker of PTEC injury, as it is highly upregulated in vivo following AKI with subsequent shedding of the ectodomain into urine ${ }^{84}$. KIM-1 outperforms traditional markers of renal function such as serum creatinine and blood urea nitrogen in early detection of injury ${ }^{85}$. Alternative biomarkers include a panel of miRNAs that are associated with various renal disease pathologies or injury ${ }^{86,87}$. Therefore, we first assessed whether HO-1 expression in the human kidney PT-MPS was affected by treatment ( 5 days; $1 \mu \mathrm{M}$ ) with either a model PSO (Drisapersen, DSP) or model PMO targeting the human papillomavirus (HPV) (Table 1). Staining for HO-1 by immunocytochemistry showed an expected perinuclear and cytoplasmic localization that was unchanged by treatment (Fig. 5b). Neither the DSP PSO nor HPV PMO significantly affected the expression of HO-1 while controlling for donor effect (Fig. 5c), indicating there was no change in intracellular redox environment. KIM-1 secretion was significantly lower in the PMO group (Fig. 5d) compared to control while controlling for time and donor effect $(p=0.043$, ANOVA, Tukey's multiple testing correction) and PSO while controlling for time and donor effect ( $p=0.01$, ANOVA, Tukey's multiple testing correction). However, the reduction was quite modest, suggesting both ASO chemistries were well tolerated in the PT-MPS when dosed at $1 \mu \mathrm{M}$ for a duration of 5 days. Next, we tested whether a KIM-1 response could be observed at a higher concentration $(10 \mu \mathrm{M})$ in base sequence matched ASOs (HPV PMO and HPV PSO). No treatment related change was observed while controlling for time and donor effect (Fig. 5f). However, secretion of miR-30e-5p is significantly increased by the DSP PSO ( $p=0.024$, ANOVA, Tukey's multiple testing correction) but not HPV PMO when treated at $10 \mu \mathrm{M}$ for $44 \mathrm{~h}$ (Fig. 5e). RNAseq of total RNA from this experiment revealed the DSP PSO significantly affected the expression of 18 genes relative to control (Table 3), while the HPV PMO did not significantly affect the expression of any genes. DSP PSO treatment mainly affected genes associated with ribosome biogenesis, transcript splicing, or inflammatory response. Several 


\begin{tabular}{|l|l|}
\hline Name & Sequence \\
\hline HOX11 G-strand-DNA oligomer sequence: & 5'-GCG CGA GGG AGG GGA GGG GAG GGG GAG AGG-3' \\
\hline HOX11 C-strand-DNA oligomer sequence: & 5'-CCT CTC CCC CTC CCC TCC CCT CCC TCG CGC-3' \\
\hline CYP3A5_intron3_G-strand-DNA oligomer sequence: & $\begin{array}{l}\text { 5'-GGG TGG CTC CTG TGT GAG ACT CTT GCT GTG TGT CAC ACC CTA } \\
\text { ATG AAC TAG AAC CTA AGG TTG CTG TGT GTC GTA CAA CTA GGG } \\
\text { TCG TAT GGA TTA CAT AAC ATA ATG ATC AAA GTC TGG CTT CCT GGG } \\
\text { TGT GGC TCC AGC TGC AGA ATC GGG-3' }\end{array}$ \\
\hline \multirow{3}{*}{ CYP3A5_intron3_C-strand-DNA oligomer sequence: } & $\begin{array}{l}\text { 5'-CCC GAT TCT GCA G CT GGA GCC ACA CCC AGG AAG CCA GAC TTT } \\
\text { GAT CAT TAT GTT ATG TAA TCC ATA CCC CTA GTT GTA CGA CAC ACA } \\
\text { GCA ACC TTA GGT TCT AGT TCA TTA GGG TGT GAC ACA CAG CAA } \\
\text { GAG TCT CAC ACA GGA GCC ACC C-3' }\end{array}$ \\
\hline CYP3A5_intron3_G-strand-RNA oligomer sequence: & $\begin{array}{l}\text { 5'-GGG UGG CUC CUG UGU GAG ACU CUU GCU GUG UGU CAC ACC } \\
\text { CUA AUG AAC UAG AAC CUA AGG UUG CUG UGU GUC GUA CAA CUA } \\
\text { GGG UCG UAU GGA UUA CAU AAC AUA AUG AUC AAA GUC UGG CUU } \\
\text { CCU GGG UGU GGC UCC AGC UGC AGA AUC GGG-3' }\end{array}$ \\
\hline
\end{tabular}

Table 2. DNA and RNA oligomers used in gel shift mobility assays.

members of the small nucleolar RNA C/D box 3 (SNORD3 or U3) family, which direct post-transcriptional cleavage of ribosomal precursor RNA and are required for proper biogenesis of the small ribosomal subunit, were increased ${ }^{88}$. Other genes that were induced include WDR74 and RNA5S9, which function in assembly of the large ribosomal subunit while RNVU1-7, RNVU1-18, and CLK1 regulate transcript splicing.

\section{Discussion}

The genetic basis of disease has long been recognized, but the molecular mechanisms driving specific disorders can be challenging to interpret and characterize. Polymorphisms in both coding and non-coding RNA can cause unpredictable effects on gene expression, and their effects on gene splicing is increasingly recognized as a primary driver of multiple diseases ${ }^{23,24}$. A classic example of this phenomenon are SNPs in the mouse SCNM1 gene, a splicing regulator of the neuronal sodium channel gene Scn8a, whose SNP-related splicing variant can convert mild-movement disorders into paralysis by simply shifting the splicing pattern of its target gene Scn8a, which is also sensitive to SNP-related alternative splicing of its own sequence ${ }^{89}$. While mutations in splicing regulators like SCNM1 have the potential to cause disease by altering both targeted and global splicing events in a cell, SNPs that alter the expression of metabolic genes like cytochromes P450 can also have profound pleiotropic effect on host metabolism and gene expression networks that drive disease. In this regard, SNPs in the CYP3A5 gene have been extensively studied, due to their tendency to suppress gene expression and promote renal disorders ${ }^{2-21}$. However, CYP3A5*3/*3 individuals harboring a null phenotype $(6986 A>G)$ are reported to unpredictably express wild-type CYP3A5 activity, presumably due to conditional correct intron 3 splicing ${ }^{20}$. While the mechanisms driving interindividual variability in $C Y P 3 A 5^{*} 3 /{ }^{*} 3$ wild-type protein expression remain unknown, particularly in renal tissues, gender specific differences in sex or dietary hormones, like estrogen, vitamin A or the vitamin D hormone, have been postulated ${ }^{20,90}$. Building off of observations that CYP3A5 gene expression is also salt-sensitive, we wanted investigate the possibility that dietary salts could also regulate the alternative splicing of $C Y P 3 A 5^{\star} 3 /{ }^{*} 3$ transcripts and help explain conflicting reports that CYP3A5 is involved in renal diseases like hypertension ${ }^{80}$. We also wanted to explore the mechanistic basis of alternative splicing in CYP3A5, using antisense oligonucleotides targeting the ${ }^{*} 3$-SNP site and other secondary structural elements in close proximity that may act in cis or trans to alter the splicing and expression of $C Y P 3 A 5^{\star} 3 /{ }^{\star} 3$ transcripts.

Here we demonstrated that blocking the ${ }^{\star} 3$-SNP with a PMO oligomer can prevent the alternative splicing and NMD of $C Y P 3 A 5^{\star} 3$ transcripts. We also investigated the possibility that a G-quadruplex (or G4) structure located near the ${ }^{\star} 3$-SNP site could play a salt-sensitive role in shifting spliceosome activity from the mutant splice acceptor site in intron 3 to the canonical exon 4 splice acceptor. Two conserved G-quadruplex candidates were identified in intron 3 leading to our confirmation of G4-structural character in a 151-base-region between the CYP3A5*3 SNP site and the exon 4 splice acceptor. G4 assembly was facilitated by $\mathrm{Na}+$ and $\mathrm{K}+$ cations, but not $\mathrm{Li}+$ cations, consistent with previously reported G4-structural behavior ${ }^{33-36,91,92}$. The action of G4 motifs in modulating pre-mRNA splicing is well established, therefore it is not surprising to observe a G4-mediated splicing shift in $C Y P 3 A 5^{\star} 3 /{ }^{*} 3$ pre-mRNA transcripts to a mature mRNA, which is translated into a functional protein.

When a termination codon (UAA, UAG, or UGA) enters the ribosomal A site, translation termination occurs; when termination precedes an EJC, NMD is initiated ${ }^{93}$. The cryptic splice acceptor in intron 3 created by the $6986 A>G$ mutation leads to a premature termination codon (PTC) upstream of the exon 4 EJC, which explains why CYP3A5 mRNA is diminished in ${ }^{*} 3{ }^{*} 3$ variants (Figs. $1 \mathrm{~b}, \mathrm{c}$ and $\left.2 \mathrm{a}\right)$. However, an ASO (CYP $3 A 5^{\star} 3 \mathrm{PMO}$ ) targeting the ${ }^{*} S N P$ site in $C Y P 3 A 5$ 's intron 3 can mask the mutant splice acceptor site and promote normal pre-mRNA processing (Fig. 1b,c). We hypothesized that spliceosome accessibility at the ${ }^{*} 3$ SNP site might similarly be modulated by G4-forming motifs found within intron 3 of the human CYP3A5 gene (Fig. 3a and Supplemental Fig. 2).

The kinetic evaluation of G-quadruplex formation indicates rapid nuclear formation of these secondary structures in the transcribed CYP3A5 pre-mRNA (Fig. 2b,c). The G4-like structure in intron 3 appears to efficiently recruit trans-acting splicing factors, including hnRNPs and SR proteins, because the splicing shift from the $6986 G>A$ site to exon 4 splice acceptor is mediated by a relatively small number of bases. These studies investigated the behavior of the putative G4-structure when exposed to biologically feasible monovalent cation 
concentrations. However, the mechanisms regulating the transport of cations into the nucleus where splicing occurs, particularly in cultured PTECs, remains unresolved.

These results are significant, because alterations in CYP3A5 expression levels can promote disease by disturbing the homeostasis of endogenous metabolites such as glucocorticoids, steroid hormones, and retinoids ${ }^{3}$. CYP3A5, unlike CYP3A4, is expressed in steroidogenic organs including the prostate, adrenals and kidney, making it a major mediator of pleiotropic, hormone signaling events ${ }^{3}$. The renal localization of CYP3A5, within the proximal tubule and collecting duct, allow for the local conversion of glucocorticoids including corticosterone to metabolic products like $6 \beta$-hydroxycorticosterone, which promote paracrine signaling and a metabolic switch from glucocorticoid to mineralocorticoid activity. Prolonged $M R$ signaling leads to enhanced salt retention, which in turn, promotes hypertension (see Fig. 6).

The CYP3A5 response to glucocorticoids requires dual activation of two, glucocorticoid response elements (GRE) in the promoter ${ }^{94}$. As mentioned above tonicity-responsive enhancer located in intron 2 of CYP3A7 also acts as an enhancer for neighboring CYP3A4 and CYP3A5 expression, through interactions with NFAT5, a binding protein that augments salt-induced $C Y P 3 A 5$ expression $^{80}$. Transcriptional CYP3A5 amplification from stress-induced release of glucocorticoids and salt intake, combined with salt retention, and vitamin D hormone insufficiency, can all contribute to hypertension via modulation of the renin-angiotensin-aldosterone-system (RAAS) (Fig. 6).

A high $\mathrm{Na}+/$ low $\mathrm{K}+$ diet also promotes hypertension and $\mathrm{K}+$ supplements can reduce blood pressure in hypertensive patients ${ }^{95,96}$. In contrast, aldosterone is normally secreted in response to hyperkalemia, and therefore the shunting of glucocorticoids to the $M R$ pathway by $C Y P 3 A 5$ during elevated stress could potentially disrupt innate $\mathrm{K}+$ feedback loops required to prevent hypokalemia. Human migration from equatorial regions that increased vitamin D insufficiency, and an increasingly high salt diet, may have reduced the fitness of the sodium sparing $C Y P 3 A 5^{\star} 1$ genotype in some populations ${ }^{97,98}$. Today, the $C Y P 3 A 5^{\star} 3$ allele is most commonly found in people of European ancestry, with allele frequencies ranging from 0.14 among sub-Saharan Africans to $>0.95$ in European populations ${ }^{98}$. CYP $3 A 5^{\star} 3$ polymorphs may have acquired an advantageous mutation in $C Y P 3 A 5$ intron 3, that slowed renal metabolism of key hormones, and alleviated the tendency to excrete $\mathrm{K}+$ and retain $\mathrm{Na}+$ during stress. However, because the SNP regulating CYP3A $5^{\star} 3$ variant expression is located near a putative G4 structure that responds to fluctuations in intracellular $\mathrm{K}+$ levels, it appears to represent a conditional mutation, rather than an obligate null mutation.

It is notable that several human GWAS studies have failed to link any CYP3A5 polymorphisms to hypertension ${ }^{10,18,19}$. This is not surprising as the confounding potential of the environment to modulate $C Y P 3 A 5^{\star} 3$ gene expression explains why penetration of the SNP phenotype is incomplete. We conclude that a G4-like structure within the CYP3A5 intron 3 forms a cation-sensitive "switch" that can suppress NMD in $C Y P 3 A 5^{\star} 3$ polymorphs. This is the first report of a transient restoration of $C Y P 3 A 5^{\star} 3 /{ }^{*} 3$ expression in vitro, potentially mediated by a G4 pre-mRNA element.

While our results suggest that gene-directed approaches targeting CYP3A5 for the treatment of HBP are viable and deserve greater consideration, ASO-induced nephrotoxicity is a hard-to-predict adverse event that may only be discovered once the molecule enters clinical trials. Consequently, new models and biomarkers need to be tested for their ability to screen for renal liabilities earlier in drug discovery to facilitate the development of safer ASOs. As backbone chemistry may be a core determinant of the safety of ASOs toward renal cells, we utilized a PT-MPS to characterize the safety of a PMO and two 2'-OMe-PSOs. KIM-1 secretion was not affected by treatment with HPV PSO or DSP PSO while being slightly reduced by HPV PMO. A previous report showed KIM-1 secretion by renal tubule cells in vitro in response to toxic locked-nucleic acid modified gapmers was sequence-dependent and variable ${ }^{99}$. Additional compounds, particularly those with sequences known to be toxic, should be tested to fully evaluate the value of KIM-1 secretion as a marker of ASO-induced injury in the PT-MPS. Likewise, secretion of miR-30e-5p needs to be evaluated with a larger matrix of 2'-OMe-PSO sequences to better determine its relationship to ASO-induced cell injury.

We also observed increased expression of genes involved in nucleoprotein activity based on ASO linkage chemistry, validating its role as a key driver of the intracellular distribution kinetics and protein binding properties of oligonucleotides. PSOs are known to associate with various RNA binding proteins to form nucleoprotein complexes $^{100-102}$. Interaction of PSOs with these ribonucleoproteins can result in displacement of endogenous RNA molecules (e.g. NEAT1 from paraspeckles) ${ }^{100}$. Interestingly, among the proteins known to bind PSOs are nucleolin (NCL1) and nucleophosmin (NPM1), both of which have roles in regulating ribosome biogenesis and function $^{103-106}$. NCL1 forms a complex with the U3 small nucleolar ribonucleoprotein (which contains SNORD3 RNAs) during the initial steps of small subunit processome formation ${ }^{107}$. Taken together, we postulate that the transcriptional response in DSP PSO treated cells may be driven by competition with endogenous molecules for nucleoprotein binding. Interestingly, toxic but not non-toxic phosphorothioate gapmers delocalize RNA binding proteins from the nucleolus in an RNAse H1-dependent manner, resulting in nucleolar stress and cell death ${ }^{108}$. While we did not observe overt cellular injury with DSP PSO treatment, the induction of genes involved in ribosome biogenesis warrants further investigation as it is an energetically demanding process.

Unlike the DSP PSO, we observed no changes in miRNA secretion or transcriptional signature with HPV PMO treatment, which strongly supports the safety of PMOs toward PTECs. However, further testing in in vivo may be required to differentiate the therapeutic value of these interpretations and we should not that differences in the metabolic stability of PSOs and PMOs in the PT-MPS model may not fairly predict their bioavailability in vivo. The inert nature of the HPV PMO is unlikely to be due to a lack of cellular entry, as activity was demonstrated in monolayer PTECs with gymnotic delivery of the $3 \mathrm{~A} 55^{*} 3 \mathrm{PMO}$ (Fig. 1d). Thus, the PMO chemistry is an optimal choice for targeting renal CYP3A5 as it exhibits an excellent safety profile with adequate pharmacology. 


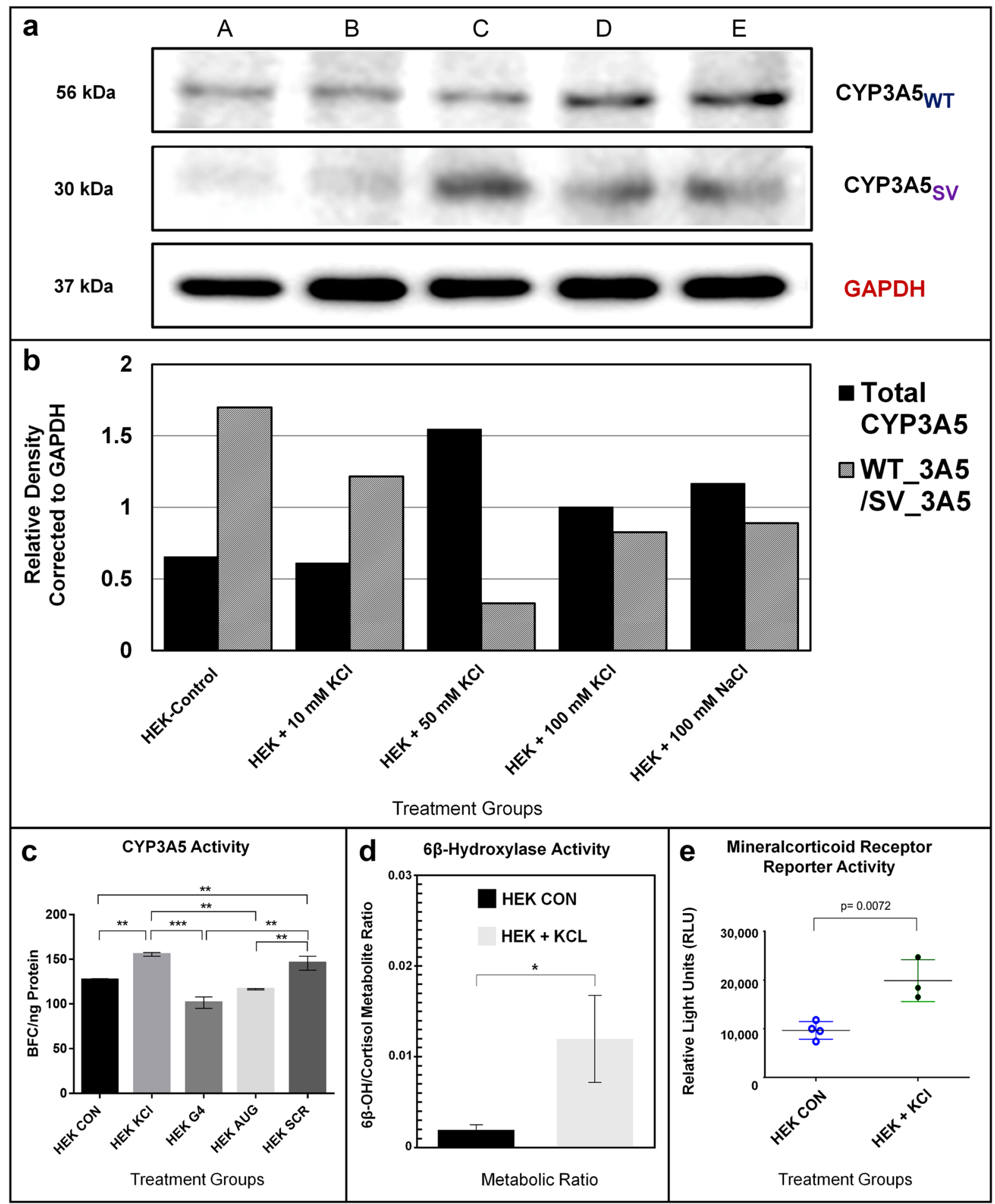


4Figure 4. Salt-Induced $C Y P 3 A 5 * 3$ Protein Expression, Enzyme Activity and Mineralocorticoid Receptor Signaling in HEK293 Cells. (a) Confluent HEK293 cells were exposed for $48 \mathrm{~h}$ to (A) control media or media supplemented with (B) $10 \mathrm{mM} \mathrm{KCl},(C) 50 \mathrm{mM} \mathrm{KCl}$, (D) $100 \mathrm{mM} \mathrm{KCl}$, or (E) $100 \mathrm{mM} \mathrm{NaCl}$. Two protein bands attributed to CYP3A5 were detected via western blot, including the full-length reference protein $\left(C Y P 3 A 5_{W T}\right)$ at 56 kilodaltons $(\mathrm{kDa})$ and a truncated $30 \mathrm{kDa}$ splice variant form $\left(C Y P 3 A 5_{s v}\right)$. The housekeeping gene $G A P D H$, detected at $37 \mathrm{kDa}$, was used to normalize sample loading. (b) Total CYP3A5 protein and the ratio of CYP3A $5_{\mathrm{WT}}$ to CYP3A5 $5_{\mathrm{SV}}$ protein normalized to $\mathrm{GAPDH}$ expression was determined using densiometric analysis in ImageJ. (c) CYP3A enzyme activity was monitored in HEK293 cells under normal conditions and with elevated $\mathrm{KCl}(12 \mathrm{mM} ; 48 \mathrm{~h}$.) and PMOs ( $1 \mu \mathrm{M} ; 48 \mathrm{~h}$.), as measured fluorometrically by BFC metabolism (see "Methods"). $\mathrm{KCl}$ supplementation significantly induced enzyme activity ( $p<0.01$; t-test) in HEK293 cells $(\mathrm{KCl})$ compared to control cells (CON). The G4 disrupting PMO (G4) and the CYP3A5 start-site inhibitor (AUG) PMO both significantly prevented $\mathrm{KCl}$ induction of $\mathrm{BFC}$ metabolism $(p<0.01$ compared to $\mathrm{KCl}$ treated control) and were not different from control cells. The scrambled (SCR) PMO control did not inhibit $\mathrm{KCl}$ induction of CYP3A activity (ANOVA $p$ value $<0.01$. Post test $p<0.01=^{* *}$, and $p<0.005=^{* * *}$ ). (d) LC MS/MS analysis of HEK293 cell media demonstrated $\mathrm{KCl}$ enrichment (12 mM, $24 \mathrm{~h}$ ) rapidly stimulated the conversion of cortisol to $6 \beta$-hydroxycortisol. An $\sim$ sixfold change in the metabolic ratio was observed for HEK293 cells grown in normal media $\left(1.93 \times 10^{-3}\right.$, solid black) compared to $12 \mathrm{mM} \mathrm{KCL}$-supplemented media $\left(1.19 \times 10^{-2}\right.$, solid gray). (e) Conditioned media from HEK293 cells (+/- KCl (12 mM); $48 \mathrm{~h}$.) were added to a luciferase-based cell reporter system for mineralocorticoid receptor (MR) transactivation (IB00501-32; Indigo Biosciences). MR activity was significantly elevated $>$ two-fold $(p<0.01$; t-test) in HEK293 media treated with $12 \mathrm{mM} \mathrm{KCl}$. The ligand-specific sensitivity of the MR activity assay was validated using a standard curve for aldosterone ( $1 \mathrm{nM}$ sensitivity $=\sim 100,000 \mathrm{RLU})$.

\section{Methods}

Reagents. DMEM (Dulbecco's Modified Eagle Medium) media and additives were obtained from Sigma (St. Louis, MO). Fetal Bovine Serum was obtained from Atlanta Biologics (Flowery Branch, GA). TMPyP4 (sc204346) was obtained from Santa Cruz Biotech (Dallas, TX). Gentest 7-benzyloxy-4-[trifluoromethyl]-coumarin (BFC; \#451730) and 7-hydroxy-4-[trifluoromethyl]-coumarin (HFC; \#451731) were obtained from Corning (Corning, NY). Cortisol (H-0888) and 63-hydroxycortisol (H-6904) were obtained from Sigma (St. Louis, MO).

Cell culture. Human embryonic kidney proximal tubule epithelial cells (HEK293), and African green monkey kidney cells (CV-1), were purchased from ATCC.org (Manassas, VA). Both cell lines were grown DMEM media plus 10\% Fetal Bovine Serum and 2 mM L-Glutamine (Corning; \#25-005-CI) supplemented with 1X PenStrep (Gibco; \#15140-122). Sanger DNA sequencing was used to validate the proper sequence of CYP3A5 gene in both cell lines (CGRB services, Oregon State University). Experimental and Scrambled Control PMOs used in cell culture experiments $(0.1-5 \mathrm{mM})$ were administered using passive uptake.

Primary human PTECs were sourced from kidney tissue obtained from patient nephrectomies at the University of Washington Medical Center in collaboration with Northwest BioTrust, as described previously ${ }^{71}$. Human PTECs were isolated as previously described (Weber et al. 2016), in accordance with a protocol approved by the University of Washington Human Subjects Institutional Review Board (IRB STUDY00001297) ${ }^{71}$. This Human Subjects study qualified for expedited review ("minimal risk"; Category 5). The kidney tissue is considered anonymized surgical waste with no patient identifying factors collected. Informed consent was obtained from all tissue donors. Cells were maintained as described previously with the exception of donor 2, which was maintained in DMEM/F12 No Glucose (US Biological, D9807-02) supplemented with 5 mM Glucose (Sigma, G7528), $14.3 \mathrm{mM}$ Sodium bicarbonate (Sigma, S-6297), ITS (sigma, I-1884-1VL), $25 \mathrm{ng} / \mathrm{mL}$ Prostaglandin E1 (Sigma, P5515), $25 \mathrm{ng} / \mathrm{mL}$ Hydrocortisone (Sigma, H-0135), $3.5 \mathrm{ug} / \mathrm{mL}$ L-Ascorbic acid (Sigma, A-4544), $3.652 \mathrm{ng} /$ mL Sodium selenite (Sigma, S-9133), 5 pM 3,3',5-Triiodo-L-thyronine sodium salt (Sigma, T-5516), $10 \mathrm{ng} / \mathrm{mL}$ rhEGF (R\&D Systems, 236-EG-200), and Antibiotic-Antimycotic (Gibco, 15240062). See Supplemental Table 1 for donor demographics.

Nucleic acid and antisense oligomer synthesis. The 8 antisense oligomers used in this study, and their targets, are listed in Table 1 along with their anticipated biological significance. The oligomers were synthesized as phosphorodiamidate morpholino oligomers (PMOs or morpholinos) by Gene-Tools, LLC (Philomath, OR, (http://www.gene-tools.com/history_production_and_properties\#preparation) as described earlier by Summerton and Weller ${ }^{109}$. Every PMO generated by Gene-Tools is accompanied by an oligomer properties specification sheet and a spectral analysis of the product to demonstrate removal of waste products by selective precipitation (synthesis resin, ammonia, cleaved base-protective groups, and minor amounts of short truncation fragments).

The 5 DNA oligomer sequences used in gel mobility studies are listed in Table 2. DNA and RNA oligomers were purchased from Integrated DNA Technologies (Coralville, IA).

Nucleic acid gel mobility shift assay. Nucleic acid mobility shift assays were performed using the method of Nambiar et al. ${ }^{110}$ Oligomers, including HOX11 C- and G-strand controls (not shown), were incubated in 10 to $100 \mathrm{mM} \mathrm{KCl}$ in Tris-EDTA buffer $\mathrm{pH} 8.0$ at $37^{\circ} \mathrm{C}$ for $1 \mathrm{~h}$. The different $\mathrm{G} 4$ structures were resolved on $12 \%$ native polyacrylamide gels in the presence of $10 \mathrm{mM} \mathrm{KCl}$ in both gel and the running buffer, at $150 \mathrm{~V}$ at $4{ }^{\circ} \mathrm{C}$. The gels were stained with ethidium bromide and photographed on a UV-transilluminator. Original uncropped and unmodified gel images for DNA and RNA gel shifts shown in Fig. 3b,c are presented in Supplemental Fig. 4. 
a

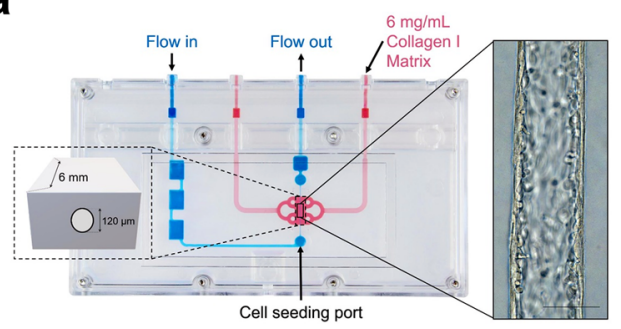

C

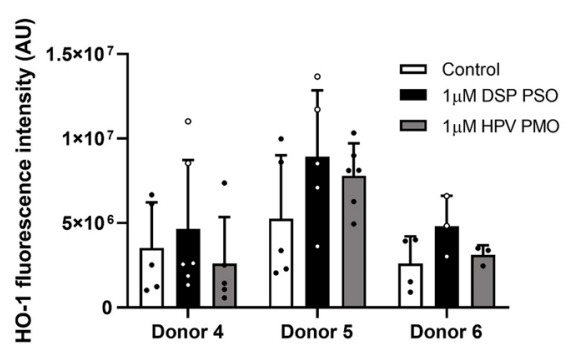

e

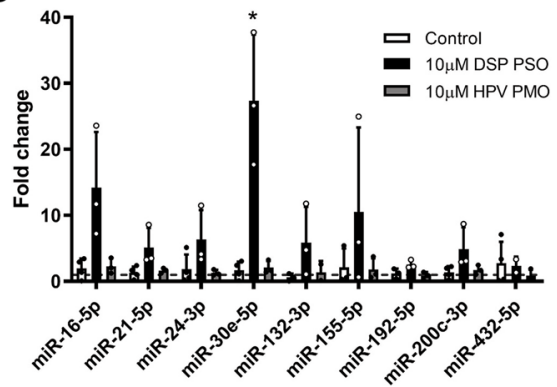

b

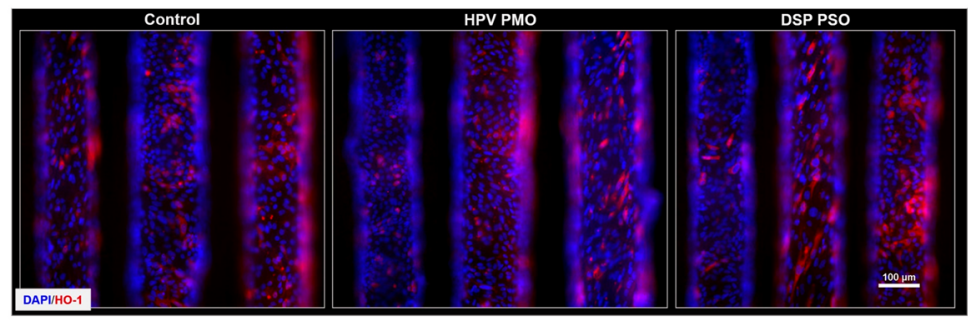

d

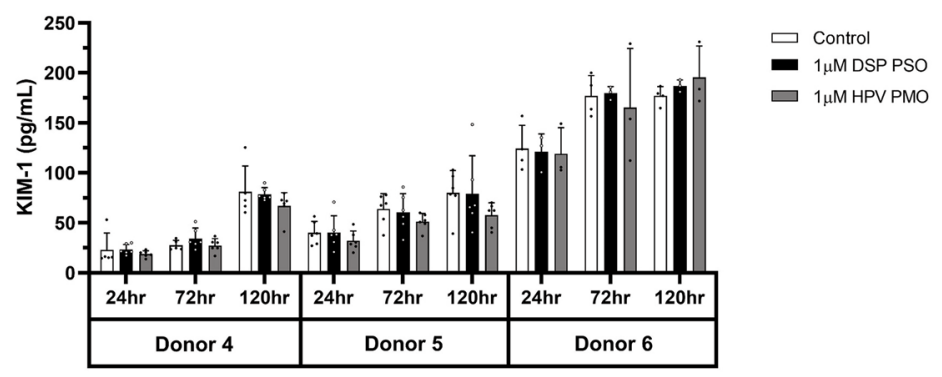

$\mathbf{f}$

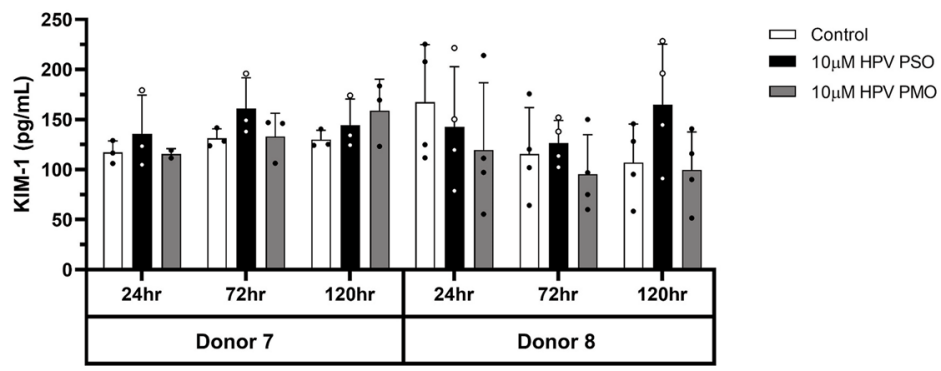

Figure 5. Safety Evaluation of ASO chemistry in PT-MPS. (a) Schematic of the PT-MPS with a phase contrast image of a confluent PTEC tubule. (b) Representative images of tubules stained for HO-1 (red) by immunocytochemistry after 5 days of treatment with $1 \mu \mathrm{M}$ HPV PMO or $1 \mu \mathrm{M}$ DSP PSO $(\mathrm{scale}=100 \mu \mathrm{m})$. Cells display a predominately perinuclear and cytoplasmic HO-1 signal. (c) Quantification of HO-1 fluorescence intensity from tubules depicted in B. Expression and localization of HO-1 is not significantly affected by HPV PMO or DSP PSO treatment. (d) Quantification of levels of KIM-1 in device effluent over time by mesoscale chemiluminescent assay after treatment with $1 \mu \mathrm{M}$ HPV PMO or $1 \mu \mathrm{M}$ DSP PSO. There is a significant reduction in KIM-1 secretion with PMO treatment compared to control ( $p=0.043$, ANOVA with Tukey's adjustment) and PSO groups ( $p=0.01$, ANOVA with Tukey's adjustment) (e) Quantification of levels of a panel of renal disease- and injury-associated miRNAs by qPCR after treatment with $10 \mu \mathrm{M}$ HPV PMO or $10 \mu \mathrm{M}$ DSP PSO for $44 \mathrm{~h}$. Data are presented as the delta-deltaC $\mathrm{T}_{\mathrm{T}}$ fold change in miRNA levels relative to control. Secretion of miR-30e-5p ( $p=0.024$, ANONVA, with Tukey's adjustment $)$ was significantly increased by DSP PSO treatment. (f) Quantification of levels of KIM-1 in device effluent over time by ELISA after treatment with $10 \mu \mathrm{M}$ HPV PMO or $10 \mu \mathrm{M}$ HPV PSO. There was no time- or dose- dependent effect of HPV PMO, DSP PSO, or HPV PSO treatment on the secretion of KIM-1. For all quantitative panels (C-F), data are presented as mean \pm s.d with black circles representing the value for each individual tubule tested.

RNA isolation and PCR analysis. Total RNA was isolated from HEK293 or CV-1 cells using the QIAshredder (Qiagen; \#79654) and RNEAsy Mini Kit (Qiagen; \#74104). RNA was treated with DnaseI (New England Biolabs; $1 \mathrm{U} / \mu \mathrm{g} \mathrm{RNA} ; 30 \mathrm{~min}$ at $37^{\circ} \mathrm{C} ; 5 \mathrm{~min}$ at $75^{\circ} \mathrm{C}$ ) to remove genomic DNA prior to reverse transcription of mRNA to cDNA using the iScript cDNA synthesis kit (Bio Rad; \#170-8890). Endpoint PCR was performed using the Platinum Taq High Fidelity DNA Polymerase kit (Invitrogen; \#11,304-011) using the manufacturer's recommended protocol with minor modifications; optimal annealing temperatures for the CYP3A5 primer sets were determined empirically, between 50 and $55{ }^{\circ} \mathrm{C}$ for $30 \mathrm{~s}$. PCR products were visualized on $1 \%$ UltraPure Agarose gels (Invitrogen; \#15510-027) prepared in 1X TBE buffer and stained with Ethidium Bromide Solution (Calbiochem; \#4410). Exon 4 inclusion in CYP3A5 mRNA transcripts was monitored using the following primer sets: hCYP3A5_dex4_FP1-5'-GGA AAC CTG GCT TCT CCT G-3' and hCYP3A5_dex4_RP1-5'-TGA CAG GCT TGC CTT TCT CT-3'. All primers were purchased from IDTDNA.com (Coralville, IA).

qRT-PCR analysis was performed using the iQ SYBR Green Supermix (BioRad; \#170-8880) in the ABI PRISM 7500 FAST Sequence Detection System (Applied Biosystems; 2 h run protocol; 96-well plate) using 


\begin{tabular}{|c|c|c|c|c|c|}
\hline $\begin{array}{l}\text { Gene } \\
\text { Symbol }\end{array}$ & Description/function & $\begin{array}{l}\text { Fold } \\
\text { change }\end{array}$ & $\log C P M$ & P-value & FDR \\
\hline WDR74 & Ribosome Assembly, large subunit & 1.72 & 8.07 & $1.27 \mathrm{E}-07$ & 0.002 \\
\hline RNA5S9 & Ribosomal RNA, large subunit & $16.19^{*}$ & 3.87 & 2.84E-06 & 0.017 \\
\hline DUSP5 & Negative Regulator of MAPK pathway & 1.60 & 5.85 & $4 \mathrm{E}-06$ & 0.017 \\
\hline RNVU1-18 & $\begin{array}{l}\text { Pseudogene of U1 small nuclear } \\
\text { spliceosomal RNA }\end{array}$ & 1.54 & 11.12 & $5.05 \mathrm{E}-06$ & 0.017 \\
\hline RNVU1-7 & $\begin{array}{l}\text { Pseudogene of U1 small nuclear } \\
\text { spliceosomal RNA }\end{array}$ & 1.53 & 8.09 & 7.18E-06 & 0.020 \\
\hline SNORD3B-1 & Guides Cleavage of pre-rRNA, small subunit & 1.48 & 9.56 & 9.69E-06 & 0.022 \\
\hline SNORD3D & Guides Cleavage of pre-rRNA, small subunit & 1.47 & 8.37 & 1.13E-05 & 0.022 \\
\hline RGS4 & Negative Regulator of G protein Signaling & 1.79 & 4.75 & 1.43E-05 & 0.025 \\
\hline MIR663AHG & Long non-coding RNA & 1.42 & 8.35 & 2.1E-05 & 0.032 \\
\hline SNORD3A & Guides cleavage of pre-rRNA, small subunit & 1.47 & 9.13 & 2.32E-05 & 0.032 \\
\hline FN1 & Extracellular Matrix Protein & 1.51 & 11.19 & 3.27E-05 & 0.037 \\
\hline SNORD3C & Guides Cleavage of pre-rRNA, small subunit & 1.50 & 8.49 & $3.34 \mathrm{E}-05$ & 0.037 \\
\hline LIF & Cytokine & 1.36 & 6.77 & 3.53E-05 & 0.037 \\
\hline ICAM1 & Adhesion Molecule & 1.56 & 5.97 & 4.05E-05 & 0.040 \\
\hline PLAUR & Tissue Reorganization & 1.82 & 5.00 & 4.47E-05 & 0.041 \\
\hline TNFAIP3 & $\begin{array}{l}\text { Deubiquitinating Protein; Negative } \\
\text { Regulator of NF-kB Pathway }\end{array}$ & 1.64 & 6.10 & $6.06 \mathrm{E}-05$ & 0.052 \\
\hline ADAMTS9 & $\begin{array}{l}\text { Metalloprotease; Protein Transport from ER } \\
\text { to Golgi }\end{array}$ & 1.36 & 8.79 & $6.42 \mathrm{E}-05$ & 0.052 \\
\hline CLK1 & $\begin{array}{c}\text { Phosphorylates Spliceosomal Complex } \\
\text { Proteins }\end{array}$ & 0.69 & 6.11 & 0.000117 & 0.090 \\
\hline
\end{tabular}

Table 3. Transcriptional response of PTECs in PT-MPS to DSP PSO treatment. Shaded rows depict genes that have functions related to nucleoprotein activity; log counts per million reads (LogCPM) is the average expression level for each gene across all samples; false discovery rate (FDR).

the manufacturer's recommended settings for SYBR Green qPCR analysis. Assays were performed in technical quadruplicates using pre-validated, Primetime qPCR primer set assays from for human target genes: CYP3A 4 (Hs.PT.58.19392980); CYP3A5 (Hs.PT.58.41063109), 18 s RNA (Hs.PT.39a.22214856.g) and ACTB (Hs.PT.39a.22214847), all obtained from Integrated DNA Technologies (Coralville, IA). Template (10-25 ng) and primer concentrations (0.5-1X Primetime mix) were optimized for each primer set to eliminate primer dimer formation in final experimental conditions. Results of 4 replicate biological samples were quantified using the 2(-Delta $\mathrm{C}(\mathrm{T})$ ) method and relative fold changes were normalized to the relative expression of $18 \mathrm{~S}$ RNA in each sample ${ }^{81}$. ACTB was chosen as an alternative internal standard but was not used to calculate the results. Standard deviation (SD) was calculated using replicate delta $\mathrm{C}_{\mathrm{T}}$ values, as described ${ }^{80}$. Microsoft Excel and GraphPad Prism were used for statistical evaluation of data, and statistical comparisons were made using the Student $\mathrm{t}$-test among individual delta $C_{\mathrm{T}}$ replicates. Statistical significance was considered at $p$ values $<0.05$. 


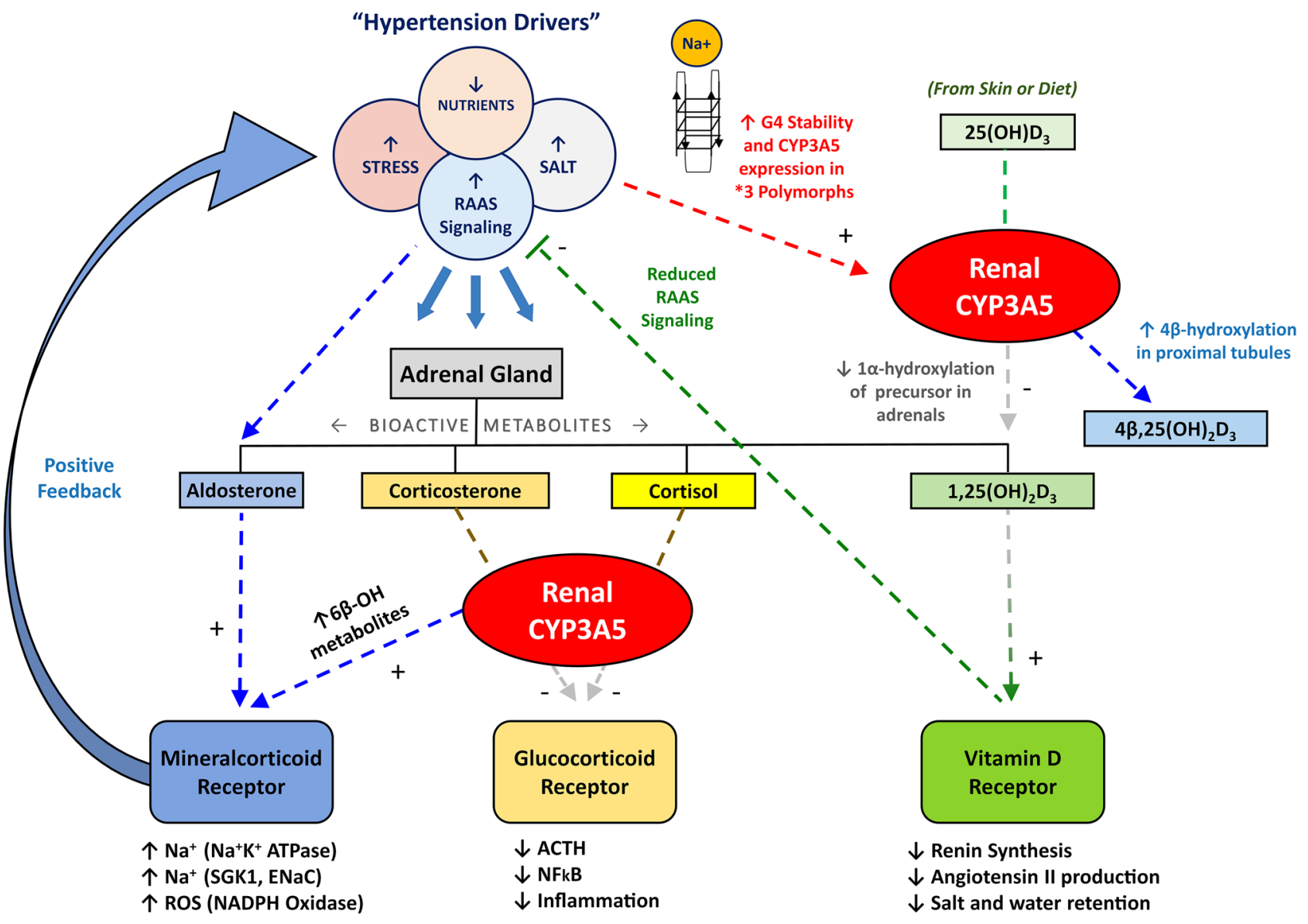

Figure 6. Schematic Diagram of CYP3A5's Dual Role in the Regulation of Hypertension. Environmental factors (e.g., diet, chemical exposure, and stress) and homeostatic signaling mechanisms (i.e., ReninAngiotensin-Aldosterone System (RAAS)) can alter renal and adrenal gland function to promote hypertension in humans. There is increasing evidence that renal CYP $3 A 5$ activity plays a dual role in modulating vitamin D- and glucocorticoid-hormone signaling cascades that drive HBP pathology. First, CYP3A5 activity can convert stress-related glucocorticoids (corticosterone and cortisol) to mineralocorticoids via 6 $\beta$-hydroxylation, which enhances MR signaling and triggers sodium retention (via several transporter related mechanisms) and increased ROS production. This activity also silences glucocorticoid signaling (via ACTH and NFkB) and increases inflammation. Second, CYP3A5 can hijack endogenous vitamin D hormone signaling cascades by shunting 25-hydroxyvitamin $\mathrm{D}_{3}$ metabolism from CYP27B1 (1 $\alpha$-hydroxylase) towards a $4 \beta$-hydroxylation pathway that limits 1,25 -dihydroxyvitamin $\mathrm{D}_{3}$ signaling via the VDR, reducing renin production that suppresses systemic RAAS activity. Thus, CYP3A5 appears to play a pathological endogenous role in many human polymorphs by regulating positive feedback loops that drives the accumulation of stress hormones and sodium in the renal proximal tubule cells. Sodium cationic-stabilization of G4-like elements in CYP3A5 intron 3 may exacerbate this hypertensive signaling arc in CYP3A $5 * 1 / * 3$ and ${ }^{\star} 3 /{ }^{*} 3$ polymorphs, who may conditionally express the gene. This salt-sensitive positive feedback loop may mask any adaptive effects of the 6986A/G polymorphism (rs776746) by promoting stress- and dietary-sensitive expression of CYP3A5, complicating any GWAS studies focused on the ${ }^{\star} 1 /{ }^{\star} 3$ or ${ }^{\star} 3 /{ }^{*}$ genotypes.

Western immunoblotting. Total protein was extracted from HEK293 and CV-1 cell lines using the RIPA Buffer Lysis System (Santa Cruz Biotech; \#sc-24948). Fresh RIPA buffer was prepared just prior to extraction and supplemented with protease inhibitors (Complete Mini; Roche; \#11777500; 1 tablet/10 mL RIPA buffer). After removing cell culture media, cells were washed with $1 \times$ PBS (VWR), and removed from plates with a rubber policeman in $1 \mathrm{~mL}$ of cold $1 \mathrm{X}$ PBS. Cells were pelleted at 3,000 rpm for $5 \mathrm{~min}$. Pellets were re-suspended in $0.75 \mathrm{~mL}$ of fresh RIPA buffer and incubated on ice for $30 \mathrm{~min}$ with intermittent vortexing. Supernatant was then separated from cell debris via centrifugation at $14,000 \times \mathrm{g}$ for $15 \mathrm{~min}$ at $4{ }^{\circ} \mathrm{C}$. Samples were then frozen at $-80^{\circ} \mathrm{C}$ or prepared for Western Blot analysis immediately via suspension into 4X Laemmli Sample Buffer (BioRad; \#161-0747) supplemented with $400 \mathrm{mM} \beta$-mercaptoethanol (Sigma; \#M6250). Western blot analysis was completed using the BioRad Mini-PROTEAN Electrophoresis System (Hercules, CA). Standard manufacturer settings and protocols were used for blotting, with minor modifications, including alternate sample preparation procedures that included the storage of proteins in fresh $1 \mathrm{X}$ Laemmli Sample buffer at $4{ }^{\circ} \mathrm{C}$, overnight, prior to boiling) to facilitate denaturation of hydrophobic target proteins. Monoclonal antibodies for human CYP $3 A 5$ 
((F18 P3 B6) were obtained from ThermoFisher Scientific (Waltham, MA; Cat\# MA3-033; RRID:AB_2090513; Ref: PMID:15897573) and used at 1-2 $\mu \mathrm{g} / \mathrm{ml}$. Monoclonal antibodies for CYP3A4 (HL3) were obtained from Santa Cruz Biotechnology, Inc. (Dallas, TX; Cat\# sc-53850; RRID:AB_782375; Ref: PMID: \# 27732883) and used at dilutions between 1:100 and 1:200. Monoclonal antibodies for the housekeeping gene GAPDH (G-9) were obtained from Santa Cruz Biotechnology, Inc. (Dallas, TX; Cat\# sc-365062; RRID:AB_10847862; Ref: PMID: 28977600) and were used at a dilution of 1:100. Total and variant CYP3A5 protein expression was determined quantitatively using grayscale, densiometric analysis in Image ${ }^{111}$. Original uncropped images for blots shown in Fig. 4a are presented in Supplemental Figs. 5-7.

CYP3A5 enzyme activity assays. HEK293 cells were incubated with substrate 7-benzyloxy4-[trifluoromethyl]-coumarin (BFC) which is converted into product 7-hydroxy-4-[trifluoromethyl]-coumarin $(\mathrm{HFC})^{112}$. The HFC was detected at excitation wavelength of $409 \mathrm{~nm}$ and emission wavelength of $530 \mathrm{~nm}$. All readings were compared to a standard curve with HFC. HEK293 cells were grown in $35 \mathrm{~mm}$ dishes in media supplemented with $1 \mathrm{nM}$ cortisol.

An LC MS/MS method was developed for simultaneous evaluation of cortisol (CORT) and 6 $\beta$-hydroxycortisol $(6 \beta \mathrm{OH})$ levels on an MDS Sciex 4000 Q TRAP LC-MS/MS System (Applied Biosystems). CORT (363 $\rightarrow 121)$ and $6 \beta \mathrm{OH}(379.3 \rightarrow 343.1)$ fragments were monitored and standard curves were prepared for each fragment. Control and conditioned media samples $(\mathrm{N}=4)$ were extracted in methylene chloride and then resuspended in $10 \%$ methanol for AUC analysis. Targeted metabolomic analysis was conducted using a Poroshell 120 EC-C18 column (Agilent; $2.1 \times 50 \mathrm{~mm}, 2.7 \mathrm{~mm}$ ) and a standard water:ethanol gradient (10-95\%) containing $5 \%$ formic acid. Standard curves $(n=3)$ for quantifying fragment ion peaks are shown in Supplemental Fig. 8.

Mineralocorticoid receptor activity. The hypothesis that CYP3A5 activity will transform glucocorticoids, cortisol, and corticosterone, into $6 \beta$-hydroxy metabolites gaining mineralocorticoid activity was evaluated using the Human MR Reporter Assay System (\#IB00501-32) from Indigo Biosciences (State Park, PA). The media from cells incubated in control media and media supplemented with $12 \mathrm{mM} \mathrm{KCl}(24 \mathrm{~h} ; \mathrm{N}=4)$ were added to a cell-based reporter system monitoring mineralocorticoid receptor (MR) transactivation as described in the manufacturer's protocol.

CYP3A5 oligonucleotide treatment in PTEC cells. PTECs passage 2-4 were seeded into uncoated 24 -well plates at 50,000 cells/well and allowed to recover for $24 \mathrm{~h}$ before treatment with PMO for 6 days. Fresh treatment media was added after $72 \mathrm{~h}$. On the 7 th day, the cells were cotreated with PMO and $1 \mu \mathrm{M}$ Midazolam (Sigma, M-908) for $24 \mathrm{~h}$.

Midazolam extraction and quantification. At the end of treatment, the supernatant was collected, and the wells were washed with $500 \mu \mathrm{L}$ methanol containing $40 \mathrm{ng} / \mathrm{mL}$ 1-OH-MDZ-d4 (Sigma, H-921) followed by another $500 \mu \mathrm{L}$ methanol wash and addition of $1 \mathrm{~mL}$ methanol to each sample. The samples were stored at -80 degrees Celsius until extraction. Standards were prepared fresh daily by spiking 1-OH-midazolam (0.0253.2 ng; Sigma, H-902) and 1-OH-MDZ-d4 (20 ng) into PTEC maintenance media. The amount of 1-OH-MDZ produced by PTECs was quantified by LC/MS-MS, as described previously with minor modification ${ }^{113}$. Briefly, the extracts were reconstituted in a 50:50 mixture of water:methanol and analytes were separated using the following gradient conditions: solvent A ( $0.1 \%$ formic acid in water) and solvent B ( $100 \%$ methanol) started at $50 \%$ for the first minute, solvent B increased linearly to $90 \%$ from 1 to $3 \mathrm{~min}$, was held at $90 \%$ until $6 \mathrm{~min}$, then returned to $50 \%$ from 6.1 to $10 \mathrm{~min}$. Mobile phases were pumped at a flow rate of $0.25 \mathrm{~mL} / \mathrm{min}$.

Generation and treatment of PT-MPS. Microfluidic devices were purchased from Nortis Biotechnology (Woodinville, WA) and PTEC tubules were generated as reported previously ${ }^{71,73}$. All tubules were allowed to culture for 5-7 days before initiating treatment. Oligonucleotide stocks were prepared to $1 \mathrm{mM}$ with water and stored at room temperature. Working solutions were prepared in PTEC maintenance media. All treatments were administered to devices via syringe-pump-driven perfusion (KD Scientific Inc., model KDS220) at a flow rate of $0.5 \mu \mathrm{L} / \mathrm{min}$.

HO-1 immunocytochemistry and quantification. All procedures were performed at room temperature and all solutions were perfused through the devices at a flow rate of $10 \mu \mathrm{L} / \mathrm{min}$. The tubules were fixed with Formalin, Buffered, 10\% (Fisher, SF100-4) for $30 \mathrm{~min}$, followed by a wash with DPBS (ThermoFisher, 14040133) for $60 \mathrm{~min}$. The devices were stored at $4{ }^{\circ} \mathrm{C}$ until further processing. To label $\mathrm{HO}-1$, the tubules were first blocked and permeabilized with dPBS containing $5 \%$ bovine serum albumin (BSA) and $0.1 \%$ Triton X-100 for $2 \mathrm{~h}$. Rabbit monoclonal anti HO-1 primary antibody (Abcam, ab52947) was diluted 1:100 in DPBS containing 5\% BSA and perfused for $1 \mathrm{~h}$, followed by a wash with DPBS containing $0.05 \%$ tween- 20 for $2 \mathrm{~h}$. Goat anti rabbit secondary (Fisher, A11037) was diluted 1:1000 in DPBS +5\%BSA and perfused for $1 \mathrm{~h}$ followed by a 2-h wash with DPBS $+0.05 \%$ Tween 20 . Nuclei were labeled with DAPI and imaged on a Nikon Eclipse Ti-S microscope. The fluorescence intensity of HO-1 labeling was quantified using ImageJ software.

KIM-1 ELISA and chemiluminescent assay. Levels of KIM-1 protein were quantified from $50 \mu \mathrm{L}$ or 100 $\mu \mathrm{L}$ of device effluents according to the manufacturer's instructions using a chemiluminescent assay (Meso Scale Discovery, K151JHD-2) or ELISA (R\&D Systems, DY1750B), respectively.

miRNA analysis. Effluent was collected over the $44 \mathrm{~h}$ and $200 \mathrm{uL}$ was used for qPCR analysis as previously described $^{73}$. 
RNA extraction and sequencing. PTECs were harvested from devices by injecting $100 \mu \mathrm{L}$ of detergent (Abcam luminescent kit, part 8206000) into the injection port using a $1 \mathrm{~mL}$ slip-tip syringe (BD, 309659) equipped with a 22-gauge needle (BD, 305142). Cell lysate was collected into $900 \mu \mathrm{L}$ Trizol and frozen at -80 degrees Celsius until extraction. RNA was isolated using a RNeasy Micro Kit (Qiagen, 74004) and the RNA library was prepared and sequenced as described previously ${ }^{73}$. Aligned data were read into $\mathrm{R}$ and summarized as counts per gene using the Bioconductor TxDb.Hsapiens.UCSC.hg38.knownGene package in concert with the GenomicAlignments package (version 3.4.0).

Statistical analysis. Data are expressed as mean and standard deviations were derived from replicate samples (at least three per treatment group). Statistical analyses were performed using GraphPad Student's twotailed $t$-test and ANOVA with Tukey-Kramer multiple comparisons test. Differences were considered significant at $p<0.05$. Statistical analysis for HO-1, KIM-1 and miRNA analysis was carried out in R (version 4.0.0) using the $\operatorname{lm}$ function, and the Anova function from the car package was used to compute two-way or 3-way ANOVA test (Type-III sums of squares). The glht function from the multcomp (version 1.4) package was used for the Tukey's multiple testing comparisons.

Statistical analysis for global transcriptomics was carried out using R (version 3.4.0). Before fitting any models, we first excluded any genes that were expressed at consistently low levels across all samples. Prior to filtering, we had 25221 genes and after filtering, we have data for 13779 genes. We then performed a trimmed mean of M-values (TMM) normalization ${ }^{114}$. To test the treatment difference, we used a GLM framework with quasilikelihood method in edgeR package (v3.18.1) $)^{115}$. Rather than using a post hoc fold change filtering criterion, we used the glmTreat function from edgeR, which is analogous to the TREAT approach ${ }^{116}$. We selected genes based on a threshold of 1.1-fold-change and a false discovery rate of $10 \%$.

Received: 21 August 2020; Accepted: 10 February 2021

Published online: 25 February 2021

\section{References}

1. Conney, A. H. Pharmacological implications of microsomal enzyme induction. Pharmacol. Rev. 19, 317-366 (1967).

2. Aoyama, T. et al. Cytochrome P-450 hPCN3, a novel cytochrome P-450 IIIA gene product that is differentially expressed in adult human liver. cDNA and deduced amino acid sequence and distinct specificities of cDNA-expressed hPCN1 and hPCN3 for the metabolism of steroid hormones and cyclosporine. J. Biol. Chem. 264, 10388-10395 (1989).

3. Koch, I. et al. Interindividual variability and tissue-specificity in the expression of cytochrome P450 3A mRNA. Drug Metab. Dispos. 30, 1108-1114. https://doi.org/10.1124/dmd.30.10.1108 (2002).

4. Bolbrinker, J. et al. CYP3A5 genotype-phenotype analysis in the human kidney reveals a strong site-specific expression of CYP3A5 in the proximal tubule in carriers of the CYP3A5 ${ }^{\star} 1$ allele. Drug Metab. Dispos. 40, 639-641. https://doi.org/10.1124/ dmd.111.042648 (2012).

5. Lamba, J. K., Lin, Y. S., Schuetz, E. G. \& Thummel, K. E. Genetic contribution to variable human CYP3A-mediated metabolism. Adv. Drug. Deliv. Rev. 54, 1271-1294. https://doi.org/10.1016/s0169-409x(02)00066-2 (2002).

6. Kuehl, P. et al. Sequence diversity in CYP3A promoters and characterization of the genetic basis of polymorphic CYP3A5 expression. Nat. Genet. 27, 383-391. https://doi.org/10.1038/86882 (2001).

7. Zheng, S. et al. CYP3A5 gene variation influences cyclosporine A metabolite formation and renal cyclosporine disposition. Transplantation 95, 821-827. https://doi.org/10.1097/TP.0b013e31827e6ad9 (2013).

8. Watlington, C. O. et al. Corticosterone 6 beta-hydroxylation correlates with blood pressure in spontaneously hypertensive rats. Am. J. Physiol. 262, F927-931. https://doi.org/10.1152/ajprenal.1992.262.6.F927 (1992).

9. Ghosh, S. S. et al. Renal and hepatic family 3A cytochromes P450 (CYP3A) in spontaneously hypertensive rats. Biochem. Pharmacol. 50, 49-54. https://doi.org/10.1016/0006-2952(95)00110-1 (1995).

10. Zhang, Y. P. et al. CYP3A5 polymorphism, amlodipine and hypertension. J. Hum. Hypertens. 28, 145-149. https://doi. org/10.1038/jhh.2013.67 (2014).

11. Lustig, S., Stern, N., Eggena, P., Tuck, M. L. \& Lee, D. B. Effect of cyclosporin on blood pressure and renin-aldosterone axis in rats. Am. J. Physiol. 253, H1596-1600. https://doi.org/10.1152/ajpheart.1987.253.6.H1596 (1987).

12. Basu, A. K., Ghosh, S., Mohanty, P. K. \& Watlington, C. O. Augmented arterial pressure responses to cyclosporine in spontaneously hypertensive rats. Role of cytochrome P-450 3A. Hypertension 24, 480-485. https://doi.org/10.1161/01.hyp.24.4.480 (1994).

13. Sacerdoti, D. et al. Treatment with tin prevents the development of hypertension in spontaneously hypertensive rats. Science 243, 388-390. https://doi.org/10.1126/science.2492116 (1989).

14. Ho, H. et al. Association between the CYP3A5 genotype and blood pressure. Hypertension 45, 294-298. https://doi. org/10.1161/01.HYP.0000151361.31736.96(2005).

15. Bochud, M. et al. Association of CYP3A5 genotypes with blood pressure and renal function in African families. J. Hypertens. 24, 923-929. https://doi.org/10.1097/01.hjh.0000222763.84605.4a (2006).

16. Givens, R. C. et al. CYP3A5 genotype predicts renal CYP3A activity and blood pressure in healthy adults. J. Appl. Physiol. 1985(95), 1297-1300. https://doi.org/10.1152/japplphysiol.00322.2003 (2003).

17. Fromm, M. F., Schmidt, B. M., Pahl, A., Jacobi, J. \& Schmieder, R. E. CYP3A5 genotype is associated with elevated blood pressure. Pharmacogenet. Genom. 15, 737-741. https://doi.org/10.1097/01.fpc.0000175599.49764.98 (2005).

18. Xi, B. et al. Association of the CYP3A5 polymorphism (6986G>A) with blood pressure and hypertension. Hypertens. Res. 34, 1216-1220. https://doi.org/10.1038/hr.2011.112 (2011).

19. Fisher, D. L. et al. CYP3A5 as a candidate gene for hypertension: no support from an unselected indigenous West African population. J. Hum. Hypertens. 30, 778-782. https://doi.org/10.1038/jhh.2016.25 (2016).

20. Lin, Y. S. et al. Co-regulation of CYP3A4 and CYP3A5 and contribution to hepatic and intestinal midazolam metabolism. Mol. Pharmacol. 62, 162-172. https://doi.org/10.1124/mol.62.1.162 (2002).

21. Moes, D. J. et al. Effect of CYP3A4*22, CYP3A $5 * 3$, and CYP3A combined genotypes on cyclosporine, everolimus, and tacrolimus pharmacokinetics in renal transplantation. CPT Pharmacomet. Syst. Pharmacol. 3, e100. https://doi.org/10.1038/psp.2013.78 (2014).

22. Merkin, J., Russell, C., Chen, P. \& Burge, C. B. Evolutionary dynamics of gene and isoform regulation in Mammalian tissues. Science 338, 1593-1599. https://doi.org/10.1126/science.1228186 (2012). 
23. Lee, Y. \& Rio, D. C. Mechanisms and regulation of alternative Pre-mRNA splicing. Annu. Rev. Biochem. 84, 291-323. https:// doi.org/10.1146/annurev-biochem-060614-034316 (2015).

24. Annalora, A. J., Marcus, C. B. \& Iversen, P. L. Alternative splicing in the cytochrome p450 superfamily expands protein diversity to augment gene function and redirect human drug metabolism. Drug Metab. Dispos. 45, 375-389. https://doi.org/10.1124/ dmd.116.073254 (2017).

25. Xiao, X. et al. Splice site strength-dependent activity and genetic buffering by poly-G runs. Nat. Struct. Mol. Biol. 16, 1094-1100. https://doi.org/10.1038/nsmb.1661 (2009).

26. Ribeiro, M. M. et al. G-quadruplex formation enhances splicing efficiency of PAX9 intron 1. Hum. Genet. 134, 37-44. https:// doi.org/10.1007/s00439-014-1485-6 (2015).

27. Marcel, V. et al. G-quadruplex structures in TP53 intron 3: role in alternative splicing and in production of p $53 \mathrm{mRNA}$ isoforms. Carcinogenesis 32, 271-278. https://doi.org/10.1093/carcin/bgq253 (2011).

28. Sirand-Pugnet, P., Durosay, P., Brody, E. \& Marie, J. An intronic (A/U)GGG repeat enhances the splicing of an alternative intron of the chicken beta-tropomyosin pre-mRNA. Nucleic Acids Res. 23, 3501-3507. https://doi.org/10.1093/nar/23.17.3501 (1995).

29. Munroe, S. H., Morales, C. H., Duyck, T. H. \& Waters, P. D. Evolution of the antisense overlap between genes for thyroid hormone receptor and rev-erbalpha and characterization of an exonic G-rich element that regulates splicing of TRalpha2 mRNA. PLoS ONE 10, e0137893. https://doi.org/10.1371/journal.pone.0137893 (2015).

30. Kralovicova, J. et al. Optimal antisense target reducing INS intron 1 retention is adjacent to a parallel G quadruplex. Nucleic Acids Res. 42, 8161-8173. https://doi.org/10.1093/nar/gku507 (2014).

31. Didiot, M. C. et al. The G-quartet containing FMRP binding site in FMR1 mRNA is a potent exonic splicing enhancer. Nucleic Acids Res. 36, 4902-4912. https://doi.org/10.1093/nar/gkn472 (2008).

32. Fisette, J. F., Montagna, D. R., Mihailescu, M. R. \& Wolfe, M. S. A G-rich element forms a G-quadruplex and regulates BACE1 mRNA alternative splicing. J. Neurochem. 121, 763-773. https://doi.org/10.1111/j.1471-4159.2012.07680.x (2012).

33. Keniry, M. A. Quadruplex structures in nucleic acids. Biopolymers 56, 123-146. https://doi.org/10.1002/10970282(2000/2001)56:3\%3c123::AID-BIP10010\%3e3.0.CO;2-3 (2000).

34. Lodish, H. F. Molecular Cell Biology. Eighth edition. edn, (W.H. Freeman-Macmillan Learning, 2016).

35. Williamson, J. R., Raghuraman, M. K. \& Cech, T. R. Monovalent cation-induced structure of telomeric DNA: the G-quartet model. Cell 59, 871-880. https://doi.org/10.1016/0092-8674(89)90610-7 (1989).

36. Neidle, S. The structures of quadruplex nucleic acids and their drug complexes. Curr. Opin. Struct. Biol. 19, 239-250. https:// doi.org/10.1016/j.sbi.2009.04.001 (2009).

37. Weldon, C. et al. Identification of G-quadruplexes in long functional RNAs using 7-deazaguanine RNA. Nat. Chem. Biol. 13, 18-20. https://doi.org/10.1038/nchembio.2228 (2017).

38. Hudziak, R. M., Summerton, J., Weller, D. D. \& Iversen, P. L. Antiproliferative effects of steric blocking phosphorodiamidate morpholino antisense agents directed against c-myc. Antisense Nucleic Acid Drug. Dev. 10, 163-176. https://doi.org/10.1089/ oli.1.2000.10.163 (2000)

39. McClorey, G. et al. Induced dystrophin exon skipping in human muscle explants. Neuromuscul. Disord. 16, 583-590. https:// doi.org/10.1016/j.nmd.2006.05.017 (2006).

40. Fall, A. M. et al. Induction of revertant fibres in the mdx mouse using antisense oligonucleotides. Genet Vaccines Ther. 4, 3. https ://doi.org/10.1186/1479-0556-4-3 (2006).

41. Fletcher, S. et al. Morpholino oligomer-mediated exon skipping averts the onset of dystrophic pathology in the mdx mouse. Mol. Ther. 15, 1587-1592. https://doi.org/10.1038/sj.mt.6300245 (2007).

42. Mitrpant, C., Fletcher, S., Iversen, P. L. \& Wilton, S. D. By-passing the nonsense mutation in the 4 CV mouse model of muscular dystrophy by induced exon skipping. J. Gene Med. 11, 46-56. https://doi.org/10.1002/jgm.1265 (2009).

43. Mourich, D. V. et al. Alternative splice forms of CTLA-4 induced by antisense mediated splice-switching influences autoimmune diabetes susceptibility in NOD mice. Nucleic Acid Ther. 24, 114-126. https://doi.org/10.1089/nat.2013.0449 (2014).

44. Panchal, R. G. et al. Induced IL-10 splice altering approach to antiviral drug discovery. Nucleic Acid Ther. 24, 179-185. https:// doi.org/10.1089/nat.2013.0457 (2014).

45. Thummel, K. E. \& Wilkinson, G. R. In vitro and in vivo drug interactions involving human CYP3A. Annu. Rev. Pharmacol. Toxicol. 38, 389-430. https://doi.org/10.1146/annurev.pharmtox.38.1.389 (1998).

46. Yu, J., Zhou, Z., Tay-Sontheimer, J., Levy, R. H. \& Ragueneau-Majlessi, I. Risk of clinically relevant pharmacokinetic-based drug-drug interactions with drugs approved by the U.S. Food and Drug Administration between 2013 and 2016. Drug. Metab. Dispos. 46, 835-845. https://doi.org/10.1124/dmd.117.078691 (2018).

47. Wright, W. C. et al. Clobetasol propionate is a heme-mediated selective inhibitor of human cytochrome P450 3A5. J. Med. Chem. 63, 1415-1433. https://doi.org/10.1021/acs.jmedchem.9b02067 (2020).

48. Del Rosso, J. Q. Topical corticosteroid therapy for psoriasis-a review of clobetasol propionate $0.025 \%$ cream and the clinical relevance of penetration modification. J. Clin. Aesthet. Dermatol. 13, 22-29 (2020).

49. Havens, M. A. \& Hastings, M. L. Splice-switching antisense oligonucleotides as therapeutic drugs. Nucleic Acids Res. 44, 65496563. https://doi.org/10.1093/nar/gkw533 (2016).

50. Bennett, C. F., Baker, B. F., Pham, N., Swayze, E. \& Geary, R. S. Pharmacology of antisense drugs. Annu. Rev. Pharmacol. Toxicol. 57, 81-105. https://doi.org/10.1146/annurev-pharmtox-010716-104846 (2017).

51. Geary, R. S. Antisense oligonucleotide pharmacokinetics and metabolism. Expert Opin. Drug. Metab. Toxicol. 5, 381-391. https ://doi.org/10.1517/17425250902877680 (2009).

52. Eckstein, F. Phosphorothioates, essential components of therapeutic oligonucleotides. Nucleic Acid Ther. 24, 374-387. https:// doi.org/10.1089/nat.2014.0506 (2014).

53. Amantana, A. \& Iversen, P. L. Pharmacokinetics and biodistribution of phosphorodiamidate morpholino antisense oligomers. Curr. Opin. Pharmacol. 5, 550-555. https://doi.org/10.1016/j.coph.2005.07.001 (2005).

54. Henry, S. P. et al. Renal uptake and tolerability of a 2'-O-methoxyethyl modified antisense oligonucleotide (ISIS 113715) in monkey. Toxicology 301, 13-20. https://doi.org/10.1016/j.tox.2012.06.005 (2012).

55. Sazani, P. et al. Repeat-dose toxicology evaluation in cynomolgus monkeys of AVI-4658, a phosphorodiamidate morpholino oligomer (PMO) drug for the treatment of duchenne muscular dystrophy. Int. J. Toxicol. 30, 313-321. https://doi.org/10.1177/10915 81811403505 (2011).

56. Komaki, H. et al. Systemic administration of the antisense oligonucleotide NS-065/NCNP-01 for skipping of exon 53 in patients with Duchenne muscular dystrophy. Sci. Transl. Med. https://doi.org/10.1126/scitranslmed.aan0713 (2018).

57. Goemans, N. M. et al. Systemic administration of PRO051 in Duchenne's muscular dystrophy. N. Engl. J. Med. 364, 1513-1522. https://doi.org/10.1056/NEJMoa1011367 (2011)

58. (ed Ionis Pharmaceuticals) (Carlsbad, CA, 2016)

59. Mendell, J. R. et al. Longitudinal effect of eteplirsen versus historical control on ambulation in Duchenne muscular dystrophy. Ann. Neurol. 79, 257-271. https://doi.org/10.1002/ana.24555 (2016).

60. Vyondys 53 (golodirsen) [package insert]. Cambridge, M. S. T.

61. Janssen, M. J. et al. Therapy with 2'-O-Me phosphorothioate antisense oligonucleotides causes reversible proteinuria by inhibiting renal protein reabsorption. Mol. Ther. Nucleic Acids 18, 298-307. https://doi.org/10.1016/j.omtn.2019.08.025 (2019). 
62. Iversen, P. L. Structure activity study of clinically observed adverse events and oligomer chemistry. J. Drug. Discov. Dev. Deliv. 3, $1022(2016)$.

63. Crooke, S. T. et al. The effects of 2'-O-methoxyethyl oligonucleotides on renal function in humans. Nucleic Acid Ther. 28, 10-22. https://doi.org/10.1089/nat.2017.0693 (2018).

64. Carver, M. P. et al. Toxicological characterization of exon skipping phosphorodiamidate morpholino oligomers (PMOs) in non-human primates. J. Neuromuscul. Dis. 3, 381-393. https://doi.org/10.3233/JND-160157 (2016).

65. Hagedorn, P. H., Hansen, B. R., Koch, T. \& Lindow, M. Managing the sequence-specificity of antisense oligonucleotides in drug discovery. Nucleic Acids Res. 45, 2262-2282. https://doi.org/10.1093/nar/gkx056 (2017).

66. Scharner, J. et al. Hybridization-mediated off-target effects of splice-switching antisense oligonucleotides. Nucleic Acids Res. 48, 802-816. https://doi.org/10.1093/nar/gkz1132 (2020).

67. van Poelgeest, E. P. et al. Acute kidney injury during therapy with an antisense oligonucleotide directed against PCSK9. Am. J. Kidney Dis. 62, 796-800. https://doi.org/10.1053/j.ajkd.2013.02.359 (2013).

68. van Meer, L. et al. Novel SGLT2 inhibitor: first-in-man studies of antisense compound is associated with unexpected renal effects. Pharmacol. Res. Perspect. 5, e00292. https://doi.org/10.1002/prp2.292 (2017).

69. van Meer, L. et al. Renal effects of antisense-mediated inhibition of SGLT2. J. Pharmacol. Exp. Ther. 359, 280-289. https://doi. org/10.1124/jpet.116.233809 (2016).

70. Herrington, W. G. et al. Association of long-term administration of the survivin mRNA-targeted antisense oligonucleotide LY2181308 with reversible kidney injury in a patient with metastatic melanoma. Am. J. Kidney Dis. 57, 300-303. https://doi. org/10.1053/j.ajkd.2010.09.024 (2011).

71. Weber, E. J. et al. Development of a microphysiological model of human kidney proximal tubule function. Kidney Int. 90, 627-637. https://doi.org/10.1016/j.kint.2016.06.011 (2016).

72. Chapron, A. et al. An improved vascularized, dual-channel microphysiological system facilitates modeling of proximal tubular solute secretion. ACS Pharmacol. Transl. Sci. https://doi.org/10.1021/acsptsci.9b00078 (2020).

73. Weber, E. J. et al. Human kidney on a chip assessment of polymyxin antibiotic nephrotoxicity. JCI Insight. https://doi.org/10.1172/ jci.insight.123673 (2018).

74. Adler, M. et al. A quantitative approach to screen for nephrotoxic compounds in vitro. J. Am. Soc. Nephrol. 27, 1015-1028. https ://doi.org/10.1681/ASN.2015010060 (2016).

75. Homan, K. A. et al. Bioprinting of 3D convoluted renal proximal tubules on perfusable chips. Sci. Rep. 6, 34845. https://doi. org $/ 10.1038 /$ srep34845 (2016).

76. Sakolish, C. et al. Technology transfer of the microphysiological systems: a case study of the human proximal tubule tissue chip. Sci. Rep. 8, 14882. https://doi.org/10.1038/s41598-018-33099-2 (2018).

77. Lin, N. Y. C. et al. Renal reabsorption in 3D vascularized proximal tubule models. Proc. Natl. Acad Sci. U. S. A. 116, 5399-5404. https://doi.org/10.1073/pnas.1815208116 (2019).

78. Jang, K. J. et al. Human kidney proximal tubule-on-a-chip for drug transport and nephrotoxicity assessment. Integr. Biol. (Camb.) 5, 1119-1129. https://doi.org/10.1039/c3ib40049b (2013).

79. Frees, S., Menendez, C., Crum, M. \& Bagga, P. S. QGRS-Conserve: a computational method for discovering evolutionarily conserved G-quadruplex motifs. Hum. Genom. 8, 8. https://doi.org/10.1186/1479-7364-8-8 (2014).

80. Kosuge, K. et al. Discovery of osmosensitive transcriptional regulation of human cytochrome P450 3As by the tonicity-responsive enhancer binding protein (nuclear factor of activated T cells 5). Mol. Pharmacol. 72, 826-837. https://doi.org/10.1124/ mol.107.034504 (2007).

81. Livak, K. J. \& Schmittgen, T. D. Analysis of relative gene expression data using real-time quantitative PCR and the 2(-Delta Delta C(T)) method. Methods 25, 402-408. https://doi.org/10.1006/meth.2001.1262 (2001).

82. Chang, Y. F., Imam, J. S. \& Wilkinson, M. F. The nonsense-mediated decay RNA surveillance pathway. Annu. Rev. Biochem. 76, 51-74. https://doi.org/10.1146/annurev.biochem (2007).

83. Saulière, J. et al. CLIP-seq of eIF4AIII reveals transcriptome-wide mapping of the human exon junction complex. Nat. Struct. Mol. Biol. 19, 1124-1131. https://doi.org/10.1038/nsmb.2420 (2012).

84. Han, W. K., Bailly, V., Abichandani, R., Thadhani, R. \& Bonventre, J. V. Kidney injury molecule-1 (KIM-1): a novel biomarker for human renal proximal tubule injury. Kidney Int. 62, 237-244. https://doi.org/10.1046/j.1523-1755.2002.00433.x (2002).

85. Vaidya, V. S. et al. Kidney injury molecule-1 outperforms traditional biomarkers of kidney injury in preclinical biomarker qualification studies. Nat. Biotechnol. 28, 478-485. https://doi.org/10.1038/nbt.1623 (2010).

86. Jenkins, R. H. et al. miR-192 induces G2/M growth arrest in aristolochic acid nephropathy. Am. J. Pathol. 184, 996-1009. https ://doi.org/10.1016/j.ajpath.2013.12.028 (2014).

87. Cardenas-Gonzalez, M. et al. Identification, confirmation, and replication of novel urinary MicroRNA biomarkers in lupus nephritis and diabetic nephropathy. Clin. Chem. 63, 1515-1526. https://doi.org/10.1373/clinchem.2017.274175 (2017).

88. Klinge, S. \& Woolford, J. L. Jr. Ribosome assembly coming into focus. Nat. Rev. Mol. Cell Biol. 20, 116-131. https://doi. org/10.1038/s41580-018-0078-y (2019).

89. Buchner, D. A., Trudeau, M. \& Meisler, M. H. SCNM1, a putative RNA splicing factor that modifies disease severity in mice. Science 301, 967-969. https://doi.org/10.1126/science (2003).

90. Dai, Y. et al. In vitro metabolism of cyclosporine A by human kidney CYP3A5. Biochem. Pharmacol. 68, 1889-1902. https://doi. org/10.1016/j.bcp.2004.07.012 (2004).

91. Basu, S. \& Wickstrom, E. Temperature and salt dependence of higher order structure formation by antisense c-myc and c-myb phosphorothioate oligodeoxyribonucleotides containing tetraguanylate tracts. Nucleic Acids Res. 25, 1327-1332. https://doi. org/10.1093/nar/25.7.1327 (1997).

92. Noer, S. L. et al. Folding dynamics and conformational heterogeneity of human telomeric G-quadruplex structures in Na+ solutions by single molecule FRET microscopy. Nucleic Acids Res. 44, 464-471. https://doi.org/10.1093/nar/gkv1320 (2016).

93. Peltz, S. W., Morsy, M., Welch, E. M. \& Jacobson, A. Ataluren as an agent for therapeutic nonsense suppression. Annu. Rev. Med. 64, 407-425. https://doi.org/10.1146/annurev-med-120611-144851 (2013).

94. Schuetz, J. D. et al. Identification of a novel dexamethasone responsive enhancer in the human CYP3A5 gene and its activation in human and rat liver cells. Mol. Pharmacol. 49, 63-72 (1996).

95. Krishna, G. G. \& Kapoor, S. C. Potassium depletion exacerbates essential hypertension. Ann. Intern. Med. 115, 77-83. https:// doi.org/10.7326/0003-4819-115-2-77 (1991).

96. Appel, L. J. et al. Dietary approaches to prevent and treat hypertension: a scientific statement from the American Heart Association. Hypertension 47, 296-308. https://doi.org/10.1161/01.HYP.0000202568.01167.B6 (2006).

97. Thompson, E. E. et al. CYP3A variation and the evolution of salt-sensitivity variants. Am. J. Hum. Genet. 75, 1059-1069. https ://doi.org/10.1086/426406 (2004).

98. Suarez-Kurtz, G. et al. Global pharmacogenomics: distribution of CYP3A5 polymorphisms and phenotypes in the Brazilian population. PLoS ONE 9, e83472. https://doi.org/10.1371/journal.pone.0083472 (2014). 
99. Moisan, A. et al. Inhibition of EGF uptake by nephrotoxic antisense drugs in vitro and implications for preclinical safety profiling. Mol. Ther. Nucleic Acids 6, 89-105. https://doi.org/10.1016/j.omtn.2016.11.006 (2017).

100. Shen, W., Liang, X. H. \& Crooke, S. T. Phosphorothioate oligonucleotides can displace NEAT1 RNA and form nuclear paraspeckle-like structures. Nucleic Acids Res. 42, 8648-8662. https://doi.org/10.1093/nar/gku579 (2014).

101. Lorenz, P., Baker, B. F., Bennett, C. F. \& Spector, D. L. Phosphorothioate antisense oligonucleotides induce the formation of nuclear bodies. Mol. Biol. Cell 9, 1007-1023. https://doi.org/10.1091/mbc.9.5.1007 (1998).

102. Wang, Y., Shen, W., Liang, X. H. \& Crooke, S. T. Phosphorothioate antisense oligonucleotides bind P-body proteins and mediate P-body assembly. Nucleic Acid Ther. 29, 343-358. https://doi.org/10.1089/nat.2019.0806 (2019).

103. Liang, X. H., Sun, H., Shen, W. \& Crooke, S. T. Identification and characterization of intracellular proteins that bind oligonucleotides with phosphorothioate linkages. Nucleic Acids Res. 43, 2927-2945. https://doi.org/10.1093/nar/gkv143 (2015).

104. Weidner, D. A., Valdez, B. C., Henning, D., Greenberg, S. \& Busch, H. Phosphorothioate oligonucleotides bind in a non sequencespecific manner to the nucleolar protein C23/nucleolin. FEBS Lett. 366, 146-150. https://doi.org/10.1016/0014-5793(95)00517 -d (1995).

105. Ginisty, H., Amalric, F. \& Bouvet, P. Nucleolin functions in the first step of ribosomal RNA processing. EMBO J. 17, 1476-1486. https://doi.org/10.1093/emboj/17.5.1476 (1998).

106. Nachmani, D. et al. Germline NPM1 mutations lead to altered rRNA 2'-O-methylation and cause dyskeratosis congenita. Nat. Genet. 51, 1518-1529. https://doi.org/10.1038/s41588-019-0502-z (2019).

107. Turner, A. J., Knox, A. A., Prieto, J. L., McStay, B. \& Watkins, N. J. A novel small-subunit processome assembly intermediate that contains the U3 snoRNP, nucleolin, RRP5, and DBP4. Mol. Cell Biol. 29, 3007-3017. https://doi.org/10.1128/MCB.00029 -09 (2009).

108. Shen, W. et al. Chemical modification of PS-ASO therapeutics reduces cellular protein-binding and improves the therapeutic index. Nat. Biotechnol. 37, 640-650. https://doi.org/10.1038/s41587-019-0106-2 (2019).

109. Summerton, J. \& Weller, D. Morpholino antisense oligomers: design, preparation, and properties. Antisense Nucleic Acid Drug Dev. 7, 187-195. https://doi.org/10.1089/oli.1.1997.7.187 (1997).

110. Nambiar, M., Srivastava, M., Gopalakrishnan, V., Sankaran, S. K. \& Raghavan, S. C. G-quadruplex structures formed at the HOX11 breakpoint region contribute to its fragility during $\mathrm{t}(10 ; 14)$ translocation in T-cell leukemia. Mol. Cell Biol. 33, 42664281. https://doi.org/10.1128/MCB.00540-13 (2013).

111. Schneider, C. A., Rasband, W. S. \& Eliceiri, K. W. NIH Image to ImageJ: 25 years of image analysis. Nat. Methods 9, 671-675. https://doi.org/10.1038/nmeth.2089 (2012).

112. Stresser, D. M. et al. Substrate-dependent modulation of CYP3A4 catalytic activity: analysis of 27 test compounds with four fluorometric substrates. Drug Metab. Dispos. 28, 1440-1448 (2000).

113. Chapron, B. et al. Reversible, time-dependent inhibition of CYP3A-mediated metabolism of midazolam and tacrolimus by telaprevir in human liver microsomes. J. Pharm. Pharm. Sci. 18, 101-111. https://doi.org/10.18433/j3288c (2015).

114. Robinson, M. D. \& Oshlack, A. A scaling normalization method for differential expression analysis of RNA-seq data. Genome Biol. 11, R25. https://doi.org/10.1186/gb-2010-11-3-r25 (2010).

115. Lun, A. T., Chen, Y. \& Smyth, G. K. It's DE-licious: a recipe for differential expression analyses of RNA-seq experiments using quasi-likelihood methods in edgeR. Methods Mol. Biol. 1418, 391-416. https://doi.org/10.1007/978-1-4939-3578-9_19 (2016).

116. McCarthy, D. J. \& Smyth, G. K. Testing significance relative to a fold-change threshold is a TREAT. Bioinformatics 25, 765-771. https://doi.org/10.1093/bioinformatics/btp053 (2009).

\section{Acknowledgements}

The authors wish to thank the Oregon State University Agricultural Research Foundation and LS Pharma for financial and material support for this project. We also wish to thank the College of Agricultural Sciences at Oregon State University, the OSU Center for Genome Research and Biocomputing, and the OSU Mass Spectrometry Center for access to their infrastructure and facilities as needed to conduct these studies. We would also like to thank the University of Washington PK Laboratory for mass spectrometry support. Research reported in this publication was supported in part by the National Institutes of Health National Center for Advancing Translational Sciences awards UG3TR002158, UH3TR002158 \& UG3TR002178, National Institute of Environmental Health Sciences Interdisciplinary Center for Exposures, Diseases, Genes and Environment (UW EDGE Center; P30ES007033)), T32 (EP\&T training grant-ES007032 - 41A1) (KAL) and the generous unrestricted gift from the Northwest Kidney Centers to the Kidney Research Institute.

\section{Author contributions}

K.L., A.A., E.K., C.M. and P.I. wrote the main manuscript text. K.L., A.A. and P.I. prepared figures. A.A., E.K., C.M. and P.I. designed experiments. K.L., A.A., M.J., D.E., L.W., T.B., S.R., and M.B.M. performed experiments and completed statistical analysis. All authors reviewed the manuscript.

\section{Competing interests}

Dr. Annalora and Dr. Iversen share a U.S. patent with Oregon State University for RENAL SELECTIVE INHIBITION OF CYTOCHROME P450 3A5 (U.S. Patent No. 10,538,769), and seven patented PMO sequences targeting human CYP3A5 (shown in Table 1) were utilized in this study. Author P.L. Iversen also has a financial interest in LS Pharma, LLC. Author's Lidberg, Jozic, Elson, Wang, Bammler, Ramm, Monteiro, Kelly and Marcus have no financial conflicts of interest to report.

\section{Additional information}

Supplementary Information The online version contains supplementary material available at https://doi. org/10.1038/s41598-021-84194-w.

Correspondence and requests for materials should be addressed to A.J.A. or E.J.K.

Reprints and permissions information is available at www.nature.com/reprints.

Publisher's note Springer Nature remains neutral with regard to jurisdictional claims in published maps and institutional affiliations. 
(c) (i) Open Access This article is licensed under a Creative Commons Attribution 4.0 International cc) License, which permits use, sharing, adaptation, distribution and reproduction in any medium or format, as long as you give appropriate credit to the original author(s) and the source, provide a link to the Creative Commons licence, and indicate if changes were made. The images or other third party material in this article are included in the article's Creative Commons licence, unless indicated otherwise in a credit line to the material. If material is not included in the article's Creative Commons licence and your intended use is not permitted by statutory regulation or exceeds the permitted use, you will need to obtain permission directly from the copyright holder. To view a copy of this licence, visit http://creativecommons.org/licenses/by/4.0/.

(C) The Author(s) 2021 